\title{
An investigation of thermodynamic states during high-pressure fuel injection using equilibrium thermodynamics
}

Lu Qiu ${ }^{1, a)}$ and Rolf D. Reitz ${ }^{1, b)}$

${ }^{1}$ Department of Mechanical Engineering, University of Wisconsin-Madison, 1500 Engineering Drive, Madison, Wisconsin, 53706, U.S.A

a): The corresponding author, email address: lqiu4@wisc.edu

${ }^{\text {b): Email address: reitz@engr.wisc.edu }}$

\begin{abstract}
A numerical investigation of mixing processes between an injected fuel (an n-alkane) and a chamber inert gas (nitrogen) was carried out for high-pressure fuel injection. The objective is to determine conditions for the coexistence of both liquid and gas phases under the typical ambient conditions encountered in diesel engines. A phenomenological investigation was built by coupling phase stability analysis with the energy conservation equation. Phase changes (including separation and combination) are predicted to occur so as to yield the lowest Gibbs free energy. It is also shown that predicted states without considering phase transitions can be very different from the corresponding thermodynamically correct states. By comparing four n-alkane/nitrogen mixtures it is shown that the lower limit of the two-phase region occurs at similar temperatures. However, heavy n-alkane/nitrogen mixtures have a larger upper limit, and phase separation occurs at higher temperatures. The present model predicts the existence of multiple phases locally in the dense spray jet under high temperature and pressure ambient conditions due to the significant reduction of the mixture temperature caused by vaporization and cooling.
\end{abstract}


Key words: Phase stability; Critical point; Supercritical; Phase transition; Condensation; Multiphase; High-pressure injection; Phase equilibrium; Thermodynamics

\section{Introduction}

Thermodynamic analysis is useful to investigate the state of a mixture, whether in one, two or more phases. Classical equilibrium thermodynamics is founded on the First and Second Laws of thermodynamics. While the First Law is similar to the conservation of energy in fluid mechanics, the importance of the Second Law is often overlooked. Specifically in thermodynamic equilibrium calculations the Second Law plays a crucial role as it presents the one and only criterion that every global stable equilibrium system must obey. For a closed thermodynamic system at specified temperature, pressure and composition, the equilibrium state has the minimum Gibbs free energy [1]. Therefore, this principle provides a very crucial phase stability criterion [2-4]. A number of research works [5-8] have used phase stability to investigate the complex phase behavior of mixtures, including liquid-liquid and vapor-liquid-liquid phase equilibria. Analogously, there is recent work studying the use of Helmholtz free energy minimization as an alternative phase stability test [9].

One special case of phase stability is the determination of the critical point (CP) lying on the stability limit. Just like for pure species, the $\mathrm{CP}$ is defined as the condition at which differences between the vapor and liquid phases vanish so that they can be considered only as one phase. For most pure species CPs can be found from databases, such as the Design Institute for Physical Properties (DIPPR) [10]. However, it is difficult to tabulate all critical properties for mixtures due to the indefinite mixture composition. 
Also, the thermodynamically true critical point of a mixture is not a simple linear function of those of its components, such as the pseudo-critical properties used in various empirical correlations $[11,12]$. In fact, in general the CP cannot be presented by an analytical equation in terms of temperature, pressure, volume and composition [13]. Therefore, there is a need to develop robust and efficient methods to calculate critical properties.

Hicks and Young [14] calculated of CPs for binary mixtures using a stepping method and the CP was identified when there was a sign change. This method was shown to be capable of finding mixture CPs, and the results for a few systems of both equal and unequal size molecules were found to agree well with previous calculations. However, the reliability of the method is questionable for mixtures with more than two components. The earliest work of Gibbs [15] founded the theoretical basis for rigorous CP calculations. Peng and Robinson [16] applied Gibbs free energy minimization to determine the CPs of multicomponent systems with their equation of state (EOS) model. Heidemann and Khalil [17] presented an alternative method using direct Helmholtz free energy minimization, which was shown to be computationally cheaper. Sadus [13] presented a thorough review of current methods in calculating CPs, including the critical transition criterion and its formulation. It was concluded that current theories and models can adequately capture the critical behavior for binary mixtures at least qualitatively, but there are still some challenges for ternary and other multicomponent mixtures. A method that can reliably predict mixture CPs called interval analysis was proposed by Stradi et al. [18].

In computational fluid dynamics (CFD) simulations, species densities, velocity and 
internal energy are solved from the governing equations of mass, momentum and energy in each numerical cell, while intensive properties like temperature and pressure are determined under the assumption of thermodynamic equilibrium [19]. For ideal gas simulations the calculation is simple since the internal energy is only a single-valued function of temperature, and pressure can then be calculated from the ideal gas law relation. However, the ideal gas law is only valid at very low pressures and cannot be extended to high pressure conditions. To mitigate this insufficiency, real gas EOS models have been applied in advanced CFD simulations [20-23], and the internal energy depends on both temperature and pressure. However, the equilibrium state must have the minimum Gibbs free energy, and a single-phase solution may not be able to satisfy this requirement. Thus, extra phases may need to be introduced to lower the Gibbs free energy [24-27]. Due to the small sizes of drops in high pressure fuel injection, spray models are generally subgrid-scale formulations, which assume that single, isolated drop correlations can be used to model vaporization and condensation processes. Moreover, the volume occupied by the liquid phase is often neglected. However, the validity of these assumptions is questionable in dense sprays, particularly if the Gibbs free energy of the local system is not tracked.

Newman and Brzustowski [28] first investigated supercritical injection of carbon dioxide into a supercritical nitrogen environment. Chehroudi [29] reviewed experimental work in high-pressure injection in liquid rockets. Experiments have shown that when fuel is injected into a chamber with pressure higher than the critical pressure of the fuel, classical liquid jet breakup phenomena diminish as droplets are hard to observe near the jet surface. In contrast, the density gradient across the shear mixing layer is found to 
reduce significantly as surface tension effects are suppressed, and "finger-like" structures instead of droplets are observed in experiments [30-34]. Planar laser induced fluorescence has been used to investigate supercritical injection and mixing with the formation of another liquid phase [35] and such experiments have been modeled by Qiu and Reitz [25]. A number of works focus on modeling supercritical flows and fuel evaporation processes under transcritical conditions [36-44]. Yang [45] presented a review of transcritical and supercritical vaporization and mixing in liquid-fueled propulsion systems. It has been pointed out that these processes are more difficult to analyze due to thermodynamic non-idealities and transport anomalies in mixing layer development under supercritical conditions [46-51].

Indeed, the existence of droplets in high-pressure sprays has been questioned [52]. In this work, fundamental thermodynamics analysis is applied to examine the thermodynamic states of mixtures during high-pressure fuel injection processes, with a special focus on exploring whether two phases can be present, as often assumed in CFD models.

\section{Model Formulation}

\subsection{Equation of state}

The Peng-Robinson (PR) equation of state [53] is used with

$$
P=\frac{R_{u} T}{v-b}-\frac{a}{v(v+b)+b(v-b)}
$$

where $P$ is pressure, $T$ is temperature, $v$ is molar volume and $R_{u}$ is the universal gas constant (8.314 J/mole-K). The two model constants $a$ and $b$, namely the attraction force and volume parameters, are calculated using: 


$$
\left\{\begin{array}{l}
a=0.457235 \frac{R_{u}^{2} T_{c}^{2}}{P_{c}} \cdot \alpha \\
b=0.077796 \frac{R_{u} T_{c}}{P_{c}} \\
\alpha=\left[1+\kappa\left(1-\sqrt{\frac{T}{T_{c}}}\right)\right]^{2}
\end{array}\right.
$$

with $\kappa$ determined using [54]

$$
\kappa= \begin{cases}0.37464+1.54226 \omega-0.26992 \omega^{2}, & \omega<0.5 \\ 0.3796+1.485 \omega-0.1644 \omega^{2}+0.01667 \omega^{3}, & \omega>0.5\end{cases}
$$

$T_{c}, P_{c}$ and $\omega$ are the critical temperature, critical pressure and acentric factor, respectively. The dimensionless parameter named compressibility factor $Z$ is calculated as

$$
Z=(P v) /\left(R_{u} T\right)
$$

Therefore, $Z$ can be considered as an indication of the departure from ideal gas behavior. Specifically, $Z$ is unity for ideal gases, but not for real (non-ideal) gases. In the case of a mixture, the classical one-fluid mixing rule is used with

$$
\left\{\begin{aligned}
a & =\sum_{i} \sum_{j} x_{i} x_{j} a_{i j} \\
b & =\sum_{i} x_{i} b_{i} \\
a_{i j} & =\left(1-\delta_{i, j}\right) \sqrt{a_{i}} \sqrt{a_{j}}
\end{aligned}\right.
$$

where $x_{i}$ is the mole fraction of species $i$ in the mixture. $\delta_{i, j}$ is the binary interaction parameter between components $i$ and $j$. For the PR EOS, the compressibility factor at the critical point for a pure species is 0.307 [53].

\subsection{Phase stability}

Phase stability analysis determines if a tested phase can stably exist. If not, phase separation occurs and the equilibrium compositions are determined through phase splitting calculations. The present phase stability analysis is based on the stability test of 
Baker et al. [3] and Michelsen [4], which is based on Gibbs' earlier work [2]. The adopted method is called the tangent plane distance (TPD) method and is calculated using:

$$
T P D(\vec{x})=\sum_{i=1}^{N_{c}} x_{i} \cdot\left(\mu_{i}(\vec{x})-\mu_{i}(\vec{z})\right)
$$

where $\vec{x}$ and $\vec{z}$ are the mole fraction and feeding compositions, respectively. $\mu$ is the chemical potential and $N_{c}$ is the number of components. It has been shown in Ref. [3] that a sufficient and necessary condition for a system to be stable is that the tangent plane at the feeding composition should not lie above the Gibbs free energy surface. The above constraint requires that the TPD function should not be negative for any possible composition of another tested phase. That is:

$$
\operatorname{TPD}(\vec{x}) \geq 0
$$

For any physically possible composition the mass conservation constraint is

$$
\left\{\begin{array}{c}
x_{i} \geq 0 \\
\sum_{i=1}^{N_{c}} x_{i}=1
\end{array}\right.
$$

Therefore, if the TPD shows any negative values for any $\vec{x}$, the mixture is deemed unstable - the original phase will separate into two or more phases [55].

\subsection{Critical point}

Starting from Gibbs's analysis, Heidemann and Khalil [17] derived a criterion for the stability of a mixture with $N_{c}$ components, viz., the quadratic term in the Taylor expansion of the Helmholtz free energy must be positive-definite. In other words, the necessary condition for stability is that there must be a non-zero perturbation array $\overline{\Delta \boldsymbol{n}}$

$$
\overline{\Delta \boldsymbol{n}}=\left(\Delta n_{1}, \Delta n_{1}, \ldots, \Delta n_{N_{c}}\right)^{T}
$$


satisfying:

$$
\boldsymbol{Q} \cdot \overline{\Delta \boldsymbol{n}}=0
$$

Here $\boldsymbol{Q}$ is a $N_{c} \times N_{c}$ matrix and its elements are determined using

$$
q_{i, j}=\left(\frac{\partial^{2} A_{H}}{\partial n_{i} \partial n_{j}}\right)_{T, V}
$$

where $A_{H}$ is the Helmholtz free energy

$$
A_{H}=U-T S
$$

$U$ and $S$ are the internal energy and entropy, respectively. $n_{i}$ is the mole number of component $i$.

For a critical point that stably lies on the stability limit, the cubic term must be zero so

$$
C=\sum_{k} \sum_{j} \sum_{i}\left(\frac{\partial^{3} A_{H}}{\partial n_{k} \partial n_{j} \partial n_{i}}\right) \cdot \Delta n_{i} \cdot \Delta n_{j} \cdot \Delta n_{k}=0
$$

It is noted that the Helmholtz free energy is selected in this formulation because commonly used EOS models, like the PR EOS, are expressed explicitly in terms of temperature, volume and mole numbers.

The following fundamental thermodynamics relations are useful when reducing the higher order derivatives (e.g., second and third order derivatives mentioned above):

$$
\left\{\begin{array}{l}
\left(\frac{\partial A_{H}}{\partial n_{i}}\right)_{T, V, n_{j \neq i}}=\mu_{i} \\
\left(\frac{\partial^{2} A_{H}}{\partial n_{i} \partial n_{j}}\right)_{T, V}=\frac{\partial \ln \left(f_{i}\right)}{\partial n_{j}}
\end{array}\right.
$$

Details on computations using the Soave-Redlich-Kwong EOS model can be found in Ref. [17]. For the adopted PR EOS of the current work, all derivatives are calculated using the corresponding derived analytical expressions (see Chapter 5 of Ref. [56]). 


\subsection{Mixing model}

To gain insight into phase change physics, for the current investigation the model of Siebers [57] shown in Fig. 1 was adopted. The fuel is injected at temperature $T_{f}$ and pressure $\mathrm{P}_{\mathrm{f}}$ into ambient air at temperature $\mathrm{T}_{\mathrm{a}}$ and pressure $\mathrm{P}_{\mathrm{a}}$. For simplicity, only nitrogen is considered as non-reacting sprays are of interest. The assumptions are [57, 58]:

(1) Mixing occurs adiabatically between the fuel and nitrogen.

(2) The kinetic energy of the fuel stream is neglected.

(3) Both the fuel and ambient streams have the same pressure. From the modeling viewpoint, the momentum equation is not needed for the static system.

(4) The equilibrium state is reached instantaneously, consistent with classical thermodynamics.

Effects of non-adiabatic and non-equilibrium mixing are discussed at the end of this paper. Applying the mass and energy equations to the constant pressure closed system yields:

$$
h\left(T_{m}, P\right)=f \cdot h\left(T_{f}, P\right)+(1-f) \cdot h\left(T_{a}, P\right)
$$

where $h, T_{f}$ and $T_{a}$ are the specific molar enthalpy, fuel and ambient temperature, respectively. $f$ is the fuel mixture mole fraction and $T_{m}$ is the adiabatic mixing temperature. It is noted that Eq. (15) is written with respect to moles, and the mixture molar enthalpy is a linear function of fuel mixture fraction. In this equation, only $T_{m}$ is unknown. 
For the PR EOS, the mixture enthalpy is calculated using the departure function [59]:

$$
\left\{\begin{aligned}
h & =h^{0}+h^{d} \\
h^{d} & =u^{d}+R_{u} T(Z-1) \\
u^{d} & =\int_{\infty}^{v}\left[T\left(\frac{\partial P}{\partial T}\right)_{v}-P\right] d v
\end{aligned}\right.
$$

where superscript " $d$ " means departure from ideal gas properties. In the following calculations, the ideal gas properties are calculated using the NASA 7-coefficient correlations [60], and the reference state is taken as $298.15 \mathrm{~K}$ and 1.0 bar. The isobaric specific heat capacity $\left(C_{P}\right)$ is calculated using:

$$
C_{P}=\left(\frac{\partial h}{\partial T}\right)_{P}=C_{V}+T\left(\frac{\partial P}{\partial T}\right)_{v}\left(\frac{\partial v}{\partial T}\right)_{P}
$$

where $C_{V}$ is the isochoric specific heat capacity. For a two-phase mixture, its thermodynamic properties, such as $h$ and $C_{P}$, are a linear function of the properties of the two phases.

A stable mixture at the calculated temperature and specified pressure must be in a state that has the minimum Gibbs free energy. Therefore, though Eq. (15) is a single function of adiabatic mixing temperature, $h\left(T_{m}, P\right)$ is also a function of the number of phases and their identities (i.e., whether liquid or vapor phase). That is, the mixture can be in a two-phase state, meaning that the energy calculation must be solved along with phase stability and phase splitting calculations. Therefore, the current investigations are fundamentally different from previous research conducted without considering phase stability (e.g., Ref. [61]). To distinguish the different treatments, the adiabatic mixing temperature from the single phase solution is termed the "Frozen Adiabatic Mixing Temperature" (FAMT), while the temperature determined from the present method using phase stability is termed the "True Adiabatic Mixing Temperature" (TAMT) in the 
following.

Note that thermodynamics only considers a homogeneous system, and all phases are distributed equally across the whole system (i.e., each numerical cell in a CFD simulation). This treatment is analogous to one-fluid models used in multiphase compressible flow simulations (e.g., Refs. [62-64] and [26, 65]). Also the partial pressure concept, which is widely used for ideal gases, does not apply for the multiphase systems investigated here. This is because (1) real gases are considered and (2) a multiphase system is considered. In other words, there is only one physical pressure for the entire thermodynamic system.

\section{Results and discussion}

\subsection{Model validations}

The present phase equilibrium solver featuring both phase stability and splitting calculations was developed by Qiu et al. [55]. It is applied here first to binary mixtures of ethane and n-heptane, and their thermodynamic properties are shown in Table 1. The interaction parameter is taken from Ref. [66]. The experimental vapor-liquid equilibrium (VLE) data is from Ref. [67]. It is seen from Fig. 2 (a) that the predictions are good for temperatures ranging from 150 to $350 \mathrm{~F}$ (338.7 to $449.8 \mathrm{~K}$ ). The liquid phase is mainly composed of n-heptane while nitrogen mainly exists in the gas phase due to its lower molar mass. The compositions of the two phases become close to each other near the critical point $(\mathrm{CP})$.

The pressure-temperature diagram is further considered for binary mixtures with $26.54 \%, 58.71 \%, 77.09 \%, 88.72 \%$ and $96.85 \%$ (mole) ethane. Comparison with the 
experimental data of Ref. [68] in Fig. 2 (b) again shows good agreement for the locations of the bubble and dew point lines, as well as the mixture CPs (which are located at the intersection of the two saturation lines). For reference, the saturation pressure lines of pure ethane and n-heptane are also included. Note that the dew pressure point can be above the mixture CPs for some mixtures, so retrograde condensation is expected, which means that an increase of pressure can not only lead to condensation, but also to evaporation.

Mixture CPs are also calculated directly and a comparison is shown in Fig. 3 with experimental data of Refs. $[67,68]$. It is seen that the CP properties are well captured. As the mole fraction of n-heptane increases, the mixture critical pressure first increases and reaches a maximum at about $20 \%$ n-heptane. Further increase of the n-heptane mole fraction reduces the mixture critical pressure. In contrast, the mixture critical temperature keeps increasing from that of pure ethane to pure n-heptane.

The present method has also been applied to binary mixtures of n-hexane $\left(\mathrm{nC}_{6} \mathrm{H}_{14}\right)$ and n-tetradecane $\left(\mathrm{nC}_{14} \mathrm{H}_{30}\right)$, and cyclohexane $\left(\mathrm{C}_{6} \mathrm{H}_{12}\right)$ and n-decane $\left(\mathrm{nC}_{10} \mathrm{H}_{22}\right)$ and good comparisons with the experimental data from Ref. [69] were seen by Qiu [70]. Additional simulations were also performed for the 32 different mixtures of Ref. [16], ranging from three-component to 12-component mixtures, and from hydrocarbon mixtures to mixtures containing nitrogen, carbon dioxide and hydrogen sulfur. Reasonably good agreement was also found for all the cases [70].

\subsection{Phase behavior of n-alkane and nitrogen mixtures}

Binary n-alkane/nitrogen mixtures were used to model the injected fuel and air in the present study. These mixtures exhibit Type III behavior according to the classical work of 
Van Konynenburg and Scott [71] for various binary mixtures, as also schematically illustrated in Fig. 4. For comparison, the phase behavior of Type I mixtures (e.g., binary hydrocarbon mixtures) is also included. For Type I mixtures there is only one critical locus line, which begins at the $\mathrm{CP}$ of one component $\mathrm{A}$ and continuously goes to the $\mathrm{CP}$ of the other component B. This behavior was observed for the mixtures investigated in Section 3.1 above (e.g., see Fig. 3). In comparison, the phase behavior of a Type III mixture is very complex as it has two branched critical locus lines. One critical locus line starts from Species A with lower critical temperature (e.g., $\mathrm{N}_{2}$ ) and ends at the CP of a three-phase (i.e., vapor-liquid-liquid equilibrium) coexistence line, which is adjacent to the saturation line of Species A. The other critical locus line starts from the high molecular weight Species B (e.g., the alkane) and it ends very precipitously at very high pressure $\left(\mathrm{P}^{\infty}\right)$, and it does not meet the $\mathrm{CP}$ of Species A. A complete discussion of the complex phase behavior of binary mixtures can be found in Refs. [13, 72, 73].

Phase equilibrium calculations for four $n$-alkane/ $\mathrm{N}_{2}$ mixtures, including $\mathrm{n}$-decane $\left(\mathrm{nC}_{10} \mathrm{H}_{22}\right)$, n-dodecane $\left(\mathrm{nC}_{12} \mathrm{H}_{26}\right)$, n-hexadecane $\left(\mathrm{nC}_{14} \mathrm{H}_{30}\right)$ and n-hexadecane $\left(\mathrm{nC}_{16} \mathrm{H}_{34}\right)$, were also performed. The thermodynamic inputs are summarized in Table 2, and the only model parameter is the binary interaction parameter, which was determined by performing VLE calculations and validating against available experimental data. The interaction parameter between $\mathrm{nC}_{10} \mathrm{H}_{22}$ and $\mathrm{N}_{2}$ was selected from Ref. [74]. A comparison of the predictions with experiments on the equilibrium nitrogen mole fraction is shown in Fig. 5 (a).

Predictions of nitrogen in the liquid phase are compared with experimental data of Refs. [75, 76] in Fig. 5 (b) for a $\mathrm{nC}_{12} \mathrm{C}_{26} / \mathrm{N}_{2}$ mixture. It is seen that the absorption of 
nitrogen into the liquid phase is well predicted and there is increasing absorption at higher temperatures. For a $\mathrm{nC}_{14} \mathrm{C}_{30} / \mathrm{N}_{2}$ mixture, the only VLE experimental data is the bubble pressure from Ref. [77], and the comparison is shown in Fig. 7. It is noticed that the predictions improve at higher temperatures. The close matches at the lowest (i.e., about $20 \%$ ) and the highest (i.e., about $90 \%$ ) $\mathrm{nC}_{14} \mathrm{C}_{30}$ composition indicates that the saturation pressure of pure $\mathrm{N}_{2}$ and pure $\mathrm{nC}_{14} \mathrm{C}_{30}$ are well captured for the current EOS model. The significant drop of saturation pressure with only some addition of nitrogen indicates that nitrogen dramatically affects the phase behavior of the mixture. In addition, it is noticed that even at pressures as high as $200 \mathrm{MPa}$, the mixture can still be in one-phase. For the $\mathrm{nC}_{16} \mathrm{C}_{34} / \mathrm{N}_{2}$ mixture, calculations in Ref. [24] show similar VLE behavior to those of Fig. 6 (a).

Good comparisons of the calculated CPs with the experimental data of Ref. [74] for $\mathrm{nC}_{10} \mathrm{H}_{22} / \mathrm{N}_{2}$ mixtures are shown in Fig. 7 (a), and similar calculations for the other three mixtures are shown in Fig. 7 (b). However, their CP data are not found in the literature or the DDBST database [76]. Some general critical behavior can be seen: as the fuel fraction decreases, the mixture critical temperature decreases but the mixture critical pressure increases; for higher fuel fractions the mixture $\mathrm{CP}$ only changes gradually, but when the fuel fraction is below 0.2 , the increasing rates of critical pressure and the decreasing rates of critical temperature both become very large. Therefore, the critical pressure and critical temperature are concave upward and concave downward functions, respectively. When the fuel fraction is 0.1 , the mixture critical pressure is above $200 \mathrm{MPa}$ and the mixture critical temperature approaches that of nitrogen. Finally, there is a systematic increase of mixture critical temperature from $\mathrm{nC}_{10} \mathrm{H}_{22} / \mathrm{N}_{2}$ to $\mathrm{nC}_{16} \mathrm{H}_{34} / \mathrm{N}_{2}$ mixtures, but a 
systematic decrease of mixture critical pressure is observed.

The corresponding critical pressure-critical temperature diagrams are shown in Fig. 8. For the $\mathrm{nC}_{10} \mathrm{H}_{22} / \mathrm{N}_{2}$ mixture, the experiments of Ref. [78] are also included. It is observed that there are significant differences in the absolute pressure for the $\mathrm{nC}_{10} \mathrm{H}_{22} / \mathrm{N}_{2}$ mixture at lower temperatures, as already analyzed above. But the general behavior of the experimental critical locus line is captured and at infinite pressure the temperature is still some distance away from the critical temperature of nitrogen, which is consistent with the schematics shown in Fig. 4. The other critical locus line is not relevant because the lowest temperature in diesel sprays is still much higher than the $\mathrm{CP}$ of pure $\mathrm{N}_{2}$.

\subsection{Adiabatic mixing}

The above validations show that the current phase stability, critical point and EOS models capture the phase behavior of alkanes in nitrogen reasonably well. Thus, fuel/air mixing processes with dynamic phase change are investigated in this section. The first two operating conditions are as in Ref. [61]: 60 bar and $900 \mathrm{~K}$ ambient condition (Condition II, ECN Spray A [79]) and 30 bar and $450 \mathrm{~K}$ (Condition I, which represents a cold engine early injection event, or a homogeneous charge gasoline engine condition [80]). An intermediate ambient condition 40 bar and $600 \mathrm{~K}$ (Condition III) was also added for the analysis below. All three conditions correspond to typical operating conditions at top dead center for a medium-duty diesel engine with an ambient gas density of about $22.8 \mathrm{~kg} / \mathrm{m}^{3}$ and the fuel temperature is $363 \mathrm{~K}$.

$\mathrm{nC}_{12} \mathrm{H}_{26} / \mathrm{N}_{2}$ is used as the main mixture but other alkanes will also be analyzed. The frozen adiabatic mixing temperature (FAMT) is shown in Fig. 9 for the two conditions, along with the stability limits. Taking Fig. 9 (b) as an example, it is seen that the mixture 
temperature drops continuously from the ambient temperature to the fuel temperature, and it is not a linear function of fuel mole fraction. The phase stability analysis shows that a single-phase solution is not stable, i.e., the mixture is not at an equilibrium state. This is also shown by the vapor-liquid equilibrium calculations of the mixture (bottom figure). As there are intersection points between the FAMT and VLE lines, the mixture enters the two-phase region, and there are two stability limits. The lower stability limit is the condition when a single-phase mixture with the smallest fuel fraction becomes unstable, which is at the point $(0.08,554.18 \mathrm{~K})$ for Condition II. This point is the "dew point" as it defines the boundary where a gaseous mixture is not stable. Similarly, the upper stability limit $(0.92,366.15 \mathrm{~K})$ is the "bubble point" as it defines the boundary where a liquid mixture is not stable and a vapor phase will form. The fuel mole fraction in the two phases between the lower and upper stability limits are shown in the top figures in Figs. 9 (a) and (b) (log scale). For Condition I, these two limits are at (0.01, $423.16 \mathrm{~K})$ and $(0.96,363.06 \mathrm{~K})$, respectively.

For the above FAMT approach, phase stability analysis and the energy equation are not fully coupled and the effects of phase change are not taken into consideration. That is, thermodynamic equilibrium is assumed, but the generated temperature does not guarantee that the system is at the equilibrium state, as seen by the two stability limits in Fig. 9. Table 3 shows the situation when phase stability is and is not considered for Condition II for fuel mixture fraction 0.2. Without phase stability, the system FAMT is $422.16 \mathrm{~K}$ and there is only one phase. In contrast, the system TAMT is $475.17 \mathrm{~K}$ when phase stability is included - a temperature difference of more than $50 \mathrm{~K}$. In addition, there are two phases for the TAMT, so phase separation has occurred for the specified conditions. In addition, 
the fuel mole fraction in the vapor phase and the vapor phase mole fraction are 10 times and $20 \%$ less due to phase change, respectively.

As shown in Fig. 10, due to the vapor phase separation at small fuel fractions, the differences between the FAMT and TAMT increase while both show a steep decrease before condensation. The maximum difference is about 80 and $50 \mathrm{~K}$ for Conditions $\mathrm{I}$ and II, respectively. The two-phase mixture prevails until the upper stability limit is reached, where phase combination occurs and only a liquid phase exists. The corresponding equilibrium distributions for the two conditions are shown in Fig. 11.

The TAMT for $\mathrm{nC}_{10} \mathrm{H}_{22} / \mathrm{N}_{2}, \mathrm{nC}_{14} \mathrm{H}_{30} / \mathrm{N}_{2}$ and $\mathrm{nC}_{16} \mathrm{H}_{34} / \mathrm{N}_{2}$, are compared in Fig. 12 for Condition II. The fuel mixture fraction at which phase separation occurs is indicated by the symbols in the blow-up plot for the four mixtures. It is seen that the lowest possible fuel mole fraction for phase change decreases systematically from $\mathrm{nC}_{10} \mathrm{H}_{22}$ to $\mathrm{nC}_{16} \mathrm{H}_{34}$, indicating that condensation is more preferable for the heaviest alkane. Figure 13 shows the specific mixture enthalpy (left) and mixture isobaric specific heat $\left(C_{P}\right)$ (right). A slope change of $C_{P}$ is observed when phase change occurs, which is most obvious for the lightest $\mathrm{nC}_{10} \mathrm{H}_{22} / \mathrm{N}_{2}$ mixture.

\subsection{Quantification of the two-phase region}

By superimposing the true adiabatic mixing temperature (TAMT) on the mixture critical locus line, the two-phase region can be determined, as shown in Figure 14 for the two conditions for the $\mathrm{nC}_{12} \mathrm{H}_{26} / \mathrm{N}_{2}$ mixture. Subcritical mixing is defined as the mixing when TAMT or pressure is lower than the corresponding mixture critical property and supercritical mixing is defined as the mixing when TAMT or pressure is higher than the corresponding mixture critical property. 
It is seen that this type of mixture cannot be in a two-phase region if the temperature is higher than the mixture critical temperature as it is also the cricondentherm, which is defined as the maximum temperature that condensation can occur at for a mixture. In contrast, a two-phase mixture is possible when the pressure is higher than the corresponding critical pressure. This is because the cricondenbar, which is defined as the maximum pressure that two-phase mixture can exist at, is always higher than the critical pressure. Therefore, supercritical temperature mixing can be considered as the sufficient condition that there cannot be two phases while a two-phase mixture can still exist stably for supercritical pressure mixing. Following these guidelines, there can be two phases for Condition I for all possible mixture compositions. In contrast, because there is a small branch (for mixture fractions from 0 to about 0.1 ) of supercritical temperature mixing for Condition II, only one phase can survive for those mixtures. Therefore, a two-phase mixture can only exist for mixtures with fuel fraction higher than 0.1 , as also seen on the pressure-temperature diagram shown in Fig. 15. Since the adiabatic operating conditions for Condition I fall on the left side of the critical locus line, the mixture can be in the two-phase region. In contrast, because of the intersection point (about 650K with fuel mixture fraction 0.044) between the adiabatic mixing and critical locus lines for Condition II, mixtures at conditions with higher temperature will be in the supercritical region (where there can only be one phase). For mixtures with lower temperatures, there is the potential to be in one phase. From the calculations above, when the temperature is below $550 \mathrm{~K}$ (fuel mixture fraction higher than 0.08 ), the mixture actually falls into the two-phase region. When the fuel mixture fraction is higher than 0.92 , the mixture is in the liquid phase as the fuel temperature is low. 
Even though the ambient temperature is higher than the critical point of the fuel, the actual mixture temperature is less due to mixing effects of the cold fuel. The above results show that such physical mixing sends the mixture back into the possible two-phase region. Typical diesel engine injection conditions ranging from (900 K, 40 bar) to $(970 \mathrm{~K}, 110 \mathrm{bar})$ are obtained from Ref. [61] and are shown in Fig. 16 for reference (see sparse crosshatch region). The corresponding predicted two-phase region for the $\mathrm{nC}_{12} \mathrm{H}_{26} / \mathrm{N}_{2}$ mixture is also shown (red dense crosshatch). The ambient operating conditions in the supercritical temperature region actually have a corresponding projected two-phase mixture region that lies to the left of the critical locus line. The calculations show that the two-phase mixture spans a wide range of mixture fractions between 0.1 and 0.9. It is hence concluded that a fuel/nitrogen mixture falls into the two-phase region under typical diesel injection conditions, and this is believed to be closely related to the Type III behavior for this type of mixture, as it has been shown above that the mixture critical pressure is so high that a two-phase state can be very easily found.

The behavior of other fuel surrogates was also investigated using $\mathrm{nC}_{10} \mathrm{H}_{22}, \mathrm{nC}_{14} \mathrm{H}_{30}$ and $\mathrm{nC}_{16} \mathrm{H}_{34}$, whose two-phase regions are also shown with the square (black), up triangle (green) and down triangle (blue) symbols in Fig. 16, respectively, and their critical locus lines are also included. It is seen that for heavier surrogates, the lower temperature limit stays almost the same, but the higher temperature limit is pushed toward the right so the two-phase region becomes larger. It is also observed that the distance between the upper temperature limit of the two-phase region and the critical locus line increases systematically going from $\mathrm{nC}_{10} \mathrm{H}_{22}$ to $\mathrm{nC}_{16} \mathrm{H}_{34}$. 


\subsection{Discussion}

It was of interest to compare the above phase equilibrium analysis with predicts made with CFD models of diesel sprays. To investigate non-adiabatic and non-equilibrium mixing effects, CFD simulations were performed with n-dodecane as the fuel and pure nitrogen as the ambient gas for three conditions similar to those for the ECN Spray A [79], as summarized in Table 4. The objective was to determine the conditions where two phases can occur locally within a diesel spray. The open-source CFD code KIVA 3V-release 2 [81] was used, which utilizes the Lagrangian-droplet-Eulerian-fluid approach to model subgrid-scale interactions between two phases. In this approach, the cold liquid fuel is injected as discrete "blobs" and the Kelvin-Helmholtz and Rayleigh-Taylor (KH-RT) breakup models [82] are used to model the primary and secondary droplet breakup. A gas-jet model [83] is used to more accurately predict gas entrainment to reduce grid dependence in the near nozzle region, and the standard $k-\varepsilon$ turbulence model is used to model the turbulence generated by the high speed fuel jet. Droplet collisions are modeled through a Radius of Influence model [84], and droplet evaporation is modeled using a discrete multicomponent model [85]. Note that no phase stability or free energy minimization is considered in these models.

The present phase stability analysis was implemented in the code and applied to the gas phase in each computational cell to examine the possibility of phase separation or supercriticality. 2D simulations were conducted with gradually increasing numerical mesh sizes with 0.07 and $0.51 \mathrm{~mm}$ in the radial and axial directions near the nozzle exit, respectively.

The predicted condensed fuel mass from previously evaporated fuel in the plume 
estimated via the KIVA subgrid-scale model is shown in Fig. 17. Here the circles represent the injected liquid droplets and the grid lines show the numerical mesh. A region of $2 \mathrm{~mm}$ in the radial direction and $10 \mathrm{~mm}$ in the axial direction is of interest. It can be seen from the contours that, with application of the present homogeneous equilibrium model, condensation is predicted to occur within the spray for all three conditions, which is consistent with the adiabatic mixing model in Section 3.4. Although the absolute mass is low (on the order of $1.0 \mathrm{e}-10 \mathrm{~g}$ ), the simulations confirm that there are subcritical regions in the spray. It is worth noting that it would be difficult to detect such small volumes of condensed phase in experiments. It is also observed that not much evaporation has taken place near the nozzle, and the condensation region occurs some distance away from the nozzle exit as it takes time for the mixing to produce an unstable mixture. For condition I, condensation is predicted to occur starting about $1.5 \mathrm{~mm}$ downstream of the nozzle exit at $0.7 \mathrm{~ms}$ after the start of injection (ASI) in Fig. 17 (a), where the temperature is relatively low compared to the ambient due to mixing with the cold fuel and the evaporative cooling. As the ambient temperature increases to $600 \mathrm{~K}$ for Condition III, it is seen in Fig. 17 (b) that the condensation region's size is reduced. In comparison, the condensed fuel region for Condition II (shown in the red box in Fig. 17 (c)) is significantly less than that for Conditions I and III, due to the higher energy density of the ambient at the higher temperature. At the same time, the local fuel mixture fraction is also generally small and condensation in the gas phase is only possible when the combination of temperature, pressure and composition produces a thermodynamically unstable mixture. The simulations show that, only in regions experiencing cooling from the vaporizing droplets are the thermodynamic conditions suitable for condensation. 
To further demonstrate the effects of non-equilibrium and non-adiabatic mixing in the sprays, the conditions in several cells in the condensation region are indicated as "A" (diamond), "B" (square) and "C" (circle) in Figs. 18 for the three conditions, and the equilibrium temperature and phase distribution are determined with the CFD predictions. It is noted that the dispersed liquid droplets are included on the right hand side of Eq. (15) in the mixing model for these spray cases. First, it is seen that the condensation cells are located only near the jet centerline where there is cooling and evaporating fuel. As a result, the local temperature from CFD simulations is significantly less than the ambient gas temperature (as seen from the data in the tables). Taking Condition II as an example, the local temperature at Point $\mathrm{B}$ is $488.3 \mathrm{~K}$ in Fig. 18 (c), which is more than $45 \%$ less than the ambient gas temperature. When considering thermodynamic equilibrium of the liquid droplets and gas phase mixture, it is further seen that the equilibrium temperature becomes even lower as local fuel mixture fraction is high and it is mainly composed of liquid droplets. As a result, there is a further $107 \mathrm{~K}$ reduction in the equilibrium temperature with consideration of phase separation.

It should also be noted that the liquid droplet phase does not account for dissolved nitrogen in standard CFD simulations while nitrogen absorption into the liquid phase is considered in the present thermodynamic analysis. Note also that, in current Lagrangian-droplet-Eulerian-fluid two-phase flow models, the liquid phase volume is assumed to be less than that of the gas phase in a numerical cell. However, it is seen in Fig. 18 that the equilibrium liquid phase fraction is generally higher than the corresponding liquid droplet fraction in some numerical cells. In summary, the comparisons show that the equilibrium analysis generally yields a lower two-phase 
mixture temperature and a larger liquid phase due to faster phase change rate. Therefore, the equilibrium treatment seems to be more suitable for analyzing high temperature and pressure dense sprays as the time scale required to reach equilibrium is significantly reduced.

The local thermodynamic conditions predicted from the spray simulations are superimposed in the predicted pressure-temperature diagram for the $\mathrm{nC}_{12} \mathrm{H}_{26} / \mathrm{N}_{2}$ mixture for the three conditions shown in Fig. 19. It is seen that the local pressures do not differ much from the ambient pressure, indicating that the constant pressure assumption used in the thermodynamic analysis is reasonable. However, local temperatures can be significantly less than the ambient gas temperature, as also predicted from the thermodynamic analysis. In fact, some numerical cells near the nozzle exit and jet centerline fall in the predicted two-phase region in Section 3.4 (see Fig. 16). Specifically for Condition II, it is seen that locally the fluid is in the two-phase region (indicated by the star symbols) due to the lower temperatures, in spite of the fact that the ambient gas temperature is high. As already predicted in Figs. 17 and 18, condensation is seen to take place locally, indicating that the conditions are conducive to the existence of both liquid and gas phases, i.e., the flow is subcritical.

Finally, for practical applications, the effects of the choice of diesel fuel surrogate should also be emphasized. The current work considers a single n-alkane species as fuel surrogate, but realistic diesel fuel is composed of hundreds of different components, including components with much higher molecular weights than those used in this work $[85,86]$. Thus, the predicted results (e.g., two-phase region locations) could be quite different, depending on the number and identities of the fuel species. 


\section{Summary and conclusions}

An investigation of high-pressure fuel injection processes is reported with a special focus on determining phase compositions. The investigation considers phase separation by coupling a rigorous phase stability analysis that is based on free energy minimization with the energy conservation equation. To model fuel and air mixing processes, n-alkane/nitrogen mixtures in a constant pressure adiabatic thermodynamic system are considered. Thermodynamic equilibrium calculations, including vapor-liquid equilibrium, phase stability and critical point calculations were performed to describe the complex phase behavior of mixtures, and the results are shown to be consistent with available experimental data. Finally, thermodynamic analysis was applied within a CFD model to determine the local states of mixtures under typical ambient conditions during diesel injection. The following conclusions can be drawn:

1) It is shown that the commonly assumed frozen single-phase calculations gives results that are not consistent with the Second Law of thermodynamics. However, consistent phase stability analysis can be performed when an appropriate equation of state model is used. Generally, the calculated temperature from the frozen flow treatment is lower than that from the thermodynamically true solution with phase change. This is due to the heat released during the formation of a new condensed phase.

2) Typical diesel injection conditions are found to include the subcritical mixing and the possibility of two-phase fuel/air mixtures, even under high temperature ambient gas conditions, especially for high molecular weight fuels. 
3) The lower temperature boundary of the two-phase area is similar for the $\mathrm{nC}_{10}$ to $\mathrm{nC}_{16}$ alkanes considered, but the upper temperature boundary increases from $\mathrm{nC}_{10} \mathrm{H}_{22}$ to $\mathrm{nC}_{16} \mathrm{H}_{34}$. Therefore, the heavier the alkane, the larger the area of the two-phase region.

4) The existence of a two-phase region was determined from the present thermodynamic equilibrium calculations at Condition II $\left(900 \mathrm{~K}, 60\right.$ bar, $\mathrm{N}_{2}$ environment).

5) Local gas phase condensation was predicted in the present CFD simulations of n-dodecane injected into a nitrogen environment, consistent with thermodynamic analysis. Especially for Condition II, even though the ambient temperature is high, there are regions where the local thermodynamic conditions fall into the two-phase region due to relatively strong heat transfer and evaporative cooling of the low temperature injected fuel.

6) When thermodynamic equilibrium and adiabatic mixing between liquid droplets and the ambient gaseous mixture is considered in dense sprays, the two-phase mixture temperature is found to be lower than that predicted from standard CFD simulations. At the same time, the equilibrium liquid phase fraction is found to be higher due to faster phase change rates, but the difference is smaller under high temperature and pressure conditions.

7) The present thermodynamic equilibrium — based methodology is a valuable limiting case for analyzing diesel injection conditions. Equilibrium analysis provides a necessary boundary condition for non-equilibrium analyses. 
8) The present methodology has also been extended to consider multicomponent fuels by Qiu [70]. For practical applications, it is important to select appropriate species to represent the fuel as the mixture phase behavior is dramatically affected by the fuel properties.

\section{Acknowledgements}

The research was conducted at the Engine Research Center of the University of Wisconsin-Madison and sponsored by the Department of Energy (DOE) and Sandia National Laboratories through the Advanced Engine Combustion Program (MOU 04-S-383) under the management of Drs. Dennis L. Siebers and Paul Miles.

\section{References}

[1] H.B. Callen, Thermodynamics and an introduction to thermostatistics, 2nd ed., J. Wiley, New York ; Chichester etc., 1985.

[2] J.W. Gibbs, A Method of Geometrical Representation of the Thermodynamic Properties of Substances by Means of Surfaces, Transaction of the Connecticut academy, II (1873) 382-404.

[3] L.E. Baker, Pierce, A.C., Luks, K.D., Gibbs Energy Analysis of Phase Equilibria SPE Journal, 22 (1982) 731-742.

[4] M.L. Michelsen, The Isothermal Flash Problem .1. Stability, Fluid Phase Equilibria, 9 (1982) 1-19.

[5] Z.D. Li, A. Firoozabadi, General Strategy for Stability Testing and Phase-Split Calculation in Two and Three Phases, SPE Journal, 17 (2012) 1096-1107.

[6] K.B. Haugen, A. Firoozabadi, L. Sun, Efficient and robust three-phase split computations, AIChE Journal, 57 (2011) 2555-2565.

[7] L.X. Nghiem, Y.K. Li, Computation of Multiphase Equilibrium Phenomena with an Equation of State, Fluid Phase Equilibria, 17 (1984) 77-95.

[8] R. Okuno, R.T. Johns, K. Sepehrnoori, Three-Phase Flash in Compositional Simulation Using a Reduced Method, SPE Journal, 15 (2010) 689-703.

[9] J. Mikyška, A. Firoozabadi, A new thermodynamic function for phase-splitting at constant temperature, moles, and volume, AIChE Journal, 57 (2011) 1897-1904.

[10] R.L. Rowley, W.V. Wilding, J.L. Oscarson, N. Giles, R.J. Rowley, T.E. Daubert, R.P. Danner, DIPPR Data Compilation of Pure Compound Properties, in, 2001.

[11] A. Kreglewski, W.B. Kay, Critical constants of conformed mixtures, The Journal of Physical Chemistry, 73 (1969) 3359-3366.

[12] C.C. Li, Critical temperature estimation for simple mixtures, The Canadian Journal of Chemical 
Engineering, 49 (1971) 709-710.

[13] R.J. Sadus, Calculating critical transitions of fluid mixtures: Theory vs. experiment, AIChE Journal, 40 (1994) 1376-1403.

[14] C.P. Hicks, C.L. Young, Theoretical prediction of phase behaviour at high temperatures and pressures for non-polar mixtures. Part 1.-Computer solution techniques and stability tests, Journal of the Chemical Society, Faraday Transactions 2: Molecular and Chemical Physics, 73 (1977) 597-612.

[15] J.W. Gibbs, On the equilibrium of heterogeneous substances, Part I, Transaction of the Connecticut academy, 3 (1876) 108-248.

[16] D.-Y. Peng, D.B. Robinson, A rigorous method for predicting the critical properties of multicomponent systems from an equation of state, AIChE Journal, 23 (1977) 137-144.

[17] R.A. Heidemann, A.M. Khalil, The calculation of critical points, AIChE Journal, 26 (1980) 769-779.

[18] B.A. Stradi, J.F. Brennecke, P. Kohn, M.A. Stadtherr, Reliable computation of mixture critical points, AIChE Journal, 47 (2001) 212-221.

[19] A.A. Amsden, O’Rourke, P. J. and Butler, T. D., KIVA-II: a computer program for chemically reactive flows with sprays, in: Technical Report LA-11560-MS, Los Alamos National Laboratory, 1989.

[20] N.A.N. Zong, V. Yang, Cryogenic fluid jets and mixing layers in transcritical and supercritical environments, Combustion Science and Technology, 178 (2006) 193-227.

[21] T. Kim, Y. Kim, S.-K. Kim, Numerical study of cryogenic liquid nitrogen jets at supercritical pressures, The Journal of Supercritical Fluids, 56 (2011) 152-163.

[22] T.S. Park, LES and RANS simulations of cryogenic liquid nitrogen jets, The Journal of Supercritical Fluids, 72 (2012) 232-247.

[23] X. Petit, G. Ribert, G. Lartigue, P. Domingo, Large-eddy simulation of supercritical fluid injection, The Journal of Supercritical Fluids, 84 (2013) 61-73.

[24] L. Qiu, R.D. Reitz, Condensation processes in a motoring engine, The Journal of Supercritical Fluids, 90 (2014) 84-100.

[25] L. Qiu, R.D. Reitz, Simulation of supercritical fuel injection with condensation, International Journal of Heat and Mass Transfer, 79 (2014) 1070-1086.

[26] L. Qiu, Y. Wang, R.D. Reitz, On regular and retrograde condensation in multiphase compressible flows, International Journal of Multiphase Flow, 64 (2014) 85-96.

[27] L. Qiu, Y. Wang, R.D. Reitz, Multiphase dynamic flash simulations using entropy maximization and application to compressible flow with phase change, AIChE Journal, 60 (2014) 3013-3024.

[28] J.A. Newman, T.A. Brzustowski, Behavior of a Liquid Jet near the Thermodynamic Critical Region, AIAA Journal, 9 (1971) 1595-1602.

[29] B. Chehroudi, Recent Experimental Efforts on High-Pressure Supercritical Injection for Liquid Rockets and Their Implications, International Journal of Aerospace Engineering, 2012 (2012) 31.

[30] T.J. Bruno, Experimental approaches for the study and application of supercritical fluids, Combustion Science and Technology, 178 (2006) 3-46.

[31] K.C. Lin, S.K. Cox-Stouffer, T.A. Jackson, Structures and phase transition processes of supercritical methane/ethylene mixtures injected into a subcritical environment, Combustion Science and 
Technology, 178 (2006) 129-160.

[32] M. Oschwald, J.J. Smith, R. Branam, J. Hussong, A. Schik, B. Chehroudi, D. Talley, Injection of fluids into supercritical environments, Combustion Science and Technology, 178 (2006) 49-100.

[33] P.-K. Wu, T.H. Chen, A.S. Nejad, C.D. Carter, Injection of supercritical ethylene in nitrogen, Journal of Propulsion and Power, 12 (1996) 770-777.

[34] B. Chehroudi, D. Talley, E. Coy, Visual characteristics and initial growth rates of round cryogenic jets at subcritical and supercritical pressures, Physics of Fluids, 14 (2002) 850-861.

[35] A. Roy, C. Joly, C. Segal, Disintegrating supercritical jets in a subcritical environment, Journal of Fluid Mechanics, 717 (2013) 193-202.

[36] J.A. Manrique, G.L. Borman, Calculations of steady state droplet vaporization at high ambient pressures, International Journal of Heat and Mass Transfer, 12 (1969) 1081-1095.

[37] G.M. Faeth, D.P. Dominicis, J.F. Tulpinsky, D.R. Olson, Supercritical bipropellant droplet combustion, Symposium (International) on Combustion, 12 (1969) 9-18.

[38] K.C. Hsieh, J.S. Shuen, V. Yang, Droplet Vaporization in High-Pressure Environments .1. Near Critical Conditions, Combustion Science and Technology, 76 (1991) 111-132.

[39] E.W. Curtis, P.V. Farrell, A Numerical Study of High-Pressure Droplet Vaporization, Combustion and Flame, 90 (1992) 85-102.

[40] G.S. Zhu, S.K. Aggarwal, Transient supercritical droplet evaporation with emphasis on the effects of equation of state, International Journal of Heat and Mass Transfer, 43 (2000) 1157-1171.

[41] J.P. Delplanque, W.A. Sirignano, Numerical Study of the Transient Vaporization of an Oxygen Droplet at Subcritical and Supercritical Conditions, International Journal of Heat and Mass Transfer, 36 (1993) 303-314.

[42] H. Jia, G. Gogos, Investigation of liquid droplet evaporation in subcritical and supercritical gaseous environments, Journal of Thermophysics and Heat Transfer, 6 (1992) 738-745.

[43] W.A. Sirignano, Fluid dynamics and transport of droplets and sprays, 2nd ed., Cambridge University Press, New York, 2010.

[44] H. Meng, V. Yang, Vaporization of two liquid oxygen (LOX) droplets in tandem in convective hydrogen streams at supercritical pressures, International Journal of Heat and Mass Transfer, 68 (2014) 500-508.

[45] V. Yang, Modeling of supercritical vaporization, mixing, and combustion processes in liquid-fueled propulsion systems, Proceedings of the Combustion Institute, 28 (2000) 925-942.

[46] J. Bellan, Supercritical (and subcritical) fluid behavior and modeling: drops, streams, shear and mixing layers, jets and sprays, Progress in Energy and Combustion Science, 26 (2000) 329-366.

[47] N. Okong'o, J. Bellan, Real-gas effects on mean flow and temporal stability of binary-species mixing layers, Aiaa Journal, 41 (2003) 2429-2443.

[48] J. Bellan, Theory, modeling and analysis of turbulent supercritical mixing, Combustion Science and Technology, 178 (2006) 253-281.

[49] L.C. Selle, N.A. Okong'o, J. Bellan, K.G. Harstad, Modelling of subgrid-scale phenomena in supercritical transitional mixing layers: an a priori study, Journal of Fluid Mechanics, 593 (2007) 57-91. 
[50] N. Okong'o, J. Bellan, Small-scale dissipation in binary-species, thermodynamically supercritical, transitional mixing layers, Computers \& Fluids, 39 (2010) 1112-1124.

[51] E. Masi, J. Bellan, K.G. Harstad, N.A. Okong'o, Multi-species turbulent mixing under supercritical-pressure conditions: modelling, direct numerical simulation and analysis revealing species spinodal decomposition, Journal of Fluid Mechanics, 721 (2013) 578-626.

[52] R.N. Dahms, J. Manin, L.M. Pickett, J.C. Oefelein, Understanding high-pressure gas-liquid interface phenomena in Diesel engines, Proceedings of the Combustion Institute, 34 (2013) 1667-1675.

[53] D.Y. Peng, D.B. Robinson, A New Two-Constant Equation of State, Industrial \& Engineering Chemistry Fundamentals, 15 (1976) 59-64.

[54] D.B. Robinson, D.Y. Peng, The characterization of the heptanes and heavier fractions for the GPA Peng-Robinson programs, in: Research report RR-28, Gas Processors Association, 1978.

[55] L. Qiu, Y. Wang, Q. Jiao, H. Wang, R.D. Reitz, Development of a thermodynamically consistent, robust and efficient phase equilibrium solver and its validations, Fuel, 115 (2014) 1-16.

[56] A. Firoozabadi, Thermodynamics of hydrocarbon reservoirs, McGraw-Hill, New York, 1999.

[57] D.L. Siebers, Scaling Liquid-Phase Fuel Penetration in Diesel Sprays Based on Mixing-Limited Vaporization, in, SAE Technical Paper 1999-01-0528, 1999.

[58] D.L. Siebers, Liquid-Phase Fuel Penetration in Diesel Sprays, SAE Paper 980809, (1998).

[59] S.I. Sandler, Chemical and engineering thermodynamics, 3rd ed., Wiley, New York, 1999.

[60] S. Gordon, B.J. McBride, Computer Program for Calculation of Complex Chemical Equilibrium Compositions and Applications: I. Analysis, NASA Reference Publication 1311, (October 1994).

[61] R.N. Dahms, J.C. Oefelein, On the transition between two-phase and single-phase interface dynamics in multicomponent fluids at supercritical pressures, Physics of Fluids, 25 (2013) 092103.

[62] D.P. Schmidt, C.J. Rutland, M.L. Corradini, A fully compressiblem, two-dimensional model of small, high-speed, cavitating nozzles, Atomization and Sprays, 9 (1999) 255-276.

[63] T.G. Liu, B.C. Khoo, W.F. Xie, Isentropic one-fluid modelling of unsteady cavitating flow, Journal of Computational Physics, 201 (2004) 80-108.

[64] W.F. Xie, T.G. Liu, B.C. Khoo, Application of a one-fluid model for large scale homogeneous unsteady cavitation: The modified Schmidt model, Computers \& Fluids, 35 (2006) 1177-1192.

[65] Y. Wang, L. Qiu, R.D. Reitz, R. Diwakar, Simulating cavitating liquid jets using a compressible and equilibrium two-phase flow solver, International Journal of Multiphase Flow, 63 (2014) 52-67.

[66] H. Nishiumi, T. Arai, K. Takeuchi, Generalization of the Binary Interaction Parameter of the Peng-Robinson Equation of State by Component Family, Fluid Phase Equilibria, 42 (1988) 43-62.

[67] V.S. Mehra, G. Thodos, Vapor-Liquid Equilibrium in the Ethane-n-Heptane System, Journal of Chemical \& Engineering Data, 10 (1965) 211-214.

[68] W.B. Kay, Liquid-Vapor Phase Equilibrium Relations in the Ethane-n-Heptane System, Industrial \& Engineering Chemistry, 30 (1938) 459-465.

[69] S.C. Pak, W.B. Kay, The Critical Properties of Binary Hydrocarbon Systems, Industrial \& Engineering Chemistry Fundamentals, 11 (1972) 255-267.

[70] L. Qiu, Development of a Phase Stability-Based Fuel Condensation Model for Advanced Low Temperature Combustion Engines, in, PhD thesis, University of Wisconsin-Madison, December, 2014. 
[71] P.H.V. Konynenburg, R.L. Scott, Critical Lines and Phase Equilibria in Binary Van Der Waals Mixtures, Philosophical Transactions of the Royal Society of London. Series A, Mathematical and Physical Sciences, 298 (1980) 495-540.

[72] P. Papon, J. Leblond, P.H.E. Meijer, The physics of phase transitions, concepts and applications, in, Springer-Verlag, Berlin ; New York, 2006.

[73] J.S. Rowlinson, F.L. Swinton, Chapter 6 - Fluid mixtures at high pressures, in: J.S.R.L. Swinton (Ed.) Liquids and Liquid Mixtures (Third edition), Butterworth-Heinemann, 1982, pp. 191-229.

[74] F. García-Sánchez, G. Eliosa-Jiménez, G. Silva-Oliver, B.E. García-Flores, Vapor-Liquid Equilibrium Data for the Nitrogen + n-Decane System from (344 to 563) K and at Pressures up to $50 \mathrm{MPa} \dagger$, Journal of Chemical \& Engineering Data, 54 (2009) 1560-1568.

[75] W. Gao, R.L. Robinson, K.A.M. Gasem, High-Pressure Solubilities of Hydrogen, Nitrogen, and Carbon Monoxide in Dodecane from 344 to $410 \mathrm{~K}$ at Pressures to $13.2 \mathrm{MPa}$, Journal of Chemical \& Engineering Data, 44 (1998) 130-132.

[76] Dortmund Data Bank, DDBST Dortmund Data Bank Software \& Separation Technology GmbH, accessed 2014, in.

[77] V.V. de Leeuw, T.W. de Loos, H.A. Kooijman, J. de Swaan Arons, The experimental determination and modelling of VLE for binary subsystems of the quaterhary system N2 + CH4 + C4H10 + C14H30 UP to 1000 bar and 440 K, Fluid Phase Equilibria, 73 (1992) 285-321.

[78] M. Wirths, Fluid-Phasengleichgewichte und kritische Erschinungen binärer Mischungen von Kohlenwasserstoffen mit Tetrafluormethan, Trifluormethan und Stickstoff zwischen $273 \mathrm{~K}$ und $630 \mathrm{~K}$ und bei Drücken bis $250 \mathrm{MPa}$, Doctoral Dissertation, in: University of Bochum, Germany, 1983.

[79] L.M. Pickett, J. Manin, C.L. Genzale, D.L. Siebers, M.P.B. Musculus, C.A. Idicheria, Relationship Between Diesel Fuel Spray Vapor Penetration/Dispersion and Local Fuel Mixture Fraction, SAE Int. J. Engines, 4 (2011) 764-799.

[80] G.S. Zhu, R.D. Reitz, Engine Fuel Droplet High-Pressure Vaporization Modeling, Journal of Engineering for Gas Turbines and Power, 123 (2000) 412-418.

[81] A.A. Amsden, KIVA-3V, Release 2, Improvements to KIVA-3V, in: Technical Report LA-UR-99-915, Los Alamos National Laboratory, 1999.

[82] J.C. Beale, R.D. Reitz, Modeling spray atomization with the Kelvin-Helmholtz/Rayleigh-Taylor hybrid model, Atomization and Sprays, 9 (1999) 623-650.

[83] N. Abani, A. Munnannur, R.D. Reitz, Reduction of numerical parameter dependencies in diesel spray models, Journal of Engineering for Gas Turbines and Power-Transactions of the ASME, 130 (2008).

[84] R.D. Reitz, A. Munnannur, Comprehensive collision model for multidimensional engine spray computations, Atomization and Sprays, 19 (2009) 597-619.

[85] Y. Ra, R.D. Reitz, A vaporization model for discrete multi-component fuel sprays, International Journal of Multiphase Flow, 35 (2009) 101-117.

[86] K. Anand, Y. Ra, R.D. Reitz, B. Bunting, Surrogate Model Development for Fuels for Advanced Combustion Engines, Energy \& Fuels, 25 (2011) 1474-1484. 


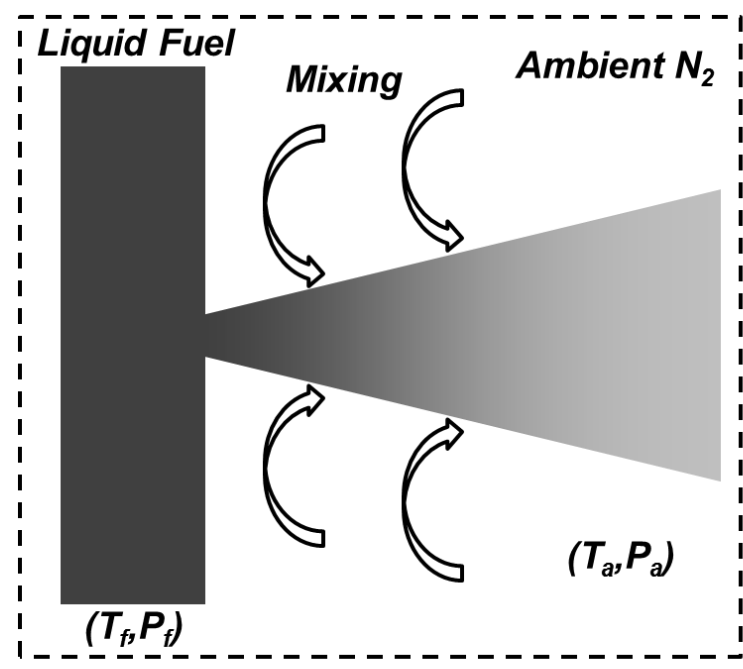

Simplified Spray

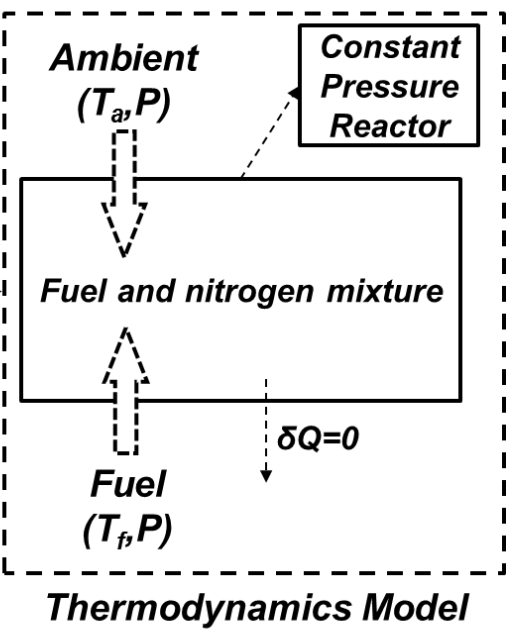

Fig. 1. Schematics showing simplified spray and thermodynamics model.

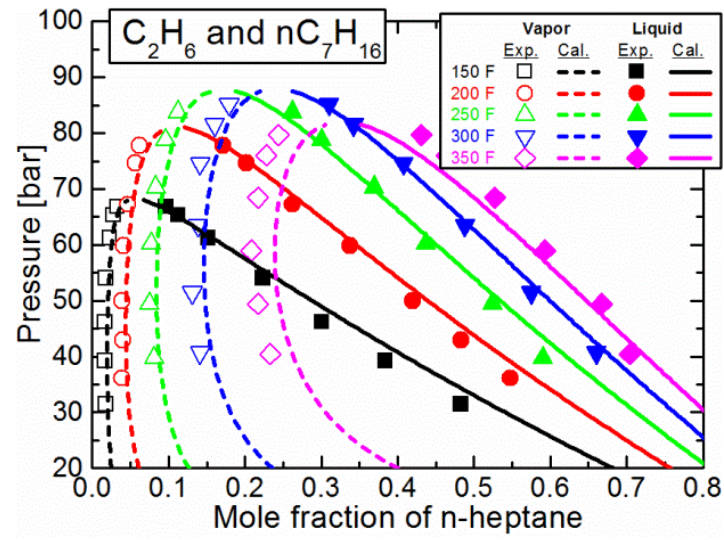

(a)

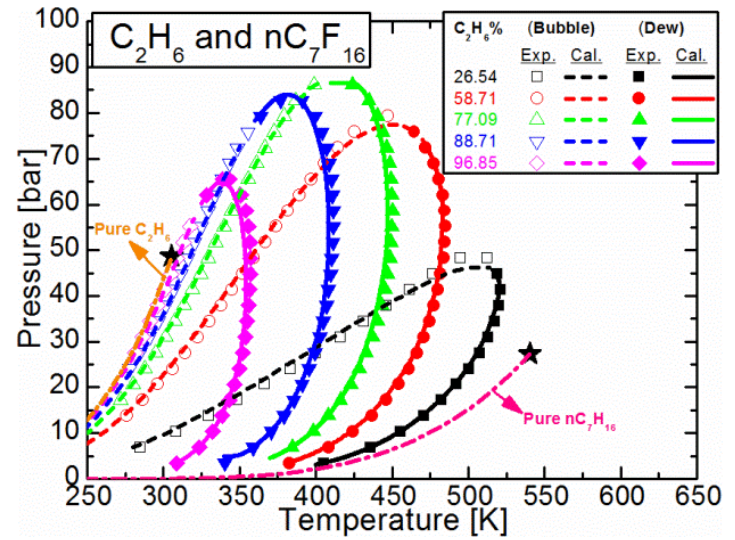

(b)

Fig. 2. Vapor-liquid equilibrium calculations of binary mixtures of ethane and n-heptane compared to experimental data. (a) Pressure-composition diagram at five temperatures (Fahrenheit). (b) Pressure-temperature diagrams of the mixture at five compositions. Saturation pressure lines of the two pure species are also shown. 


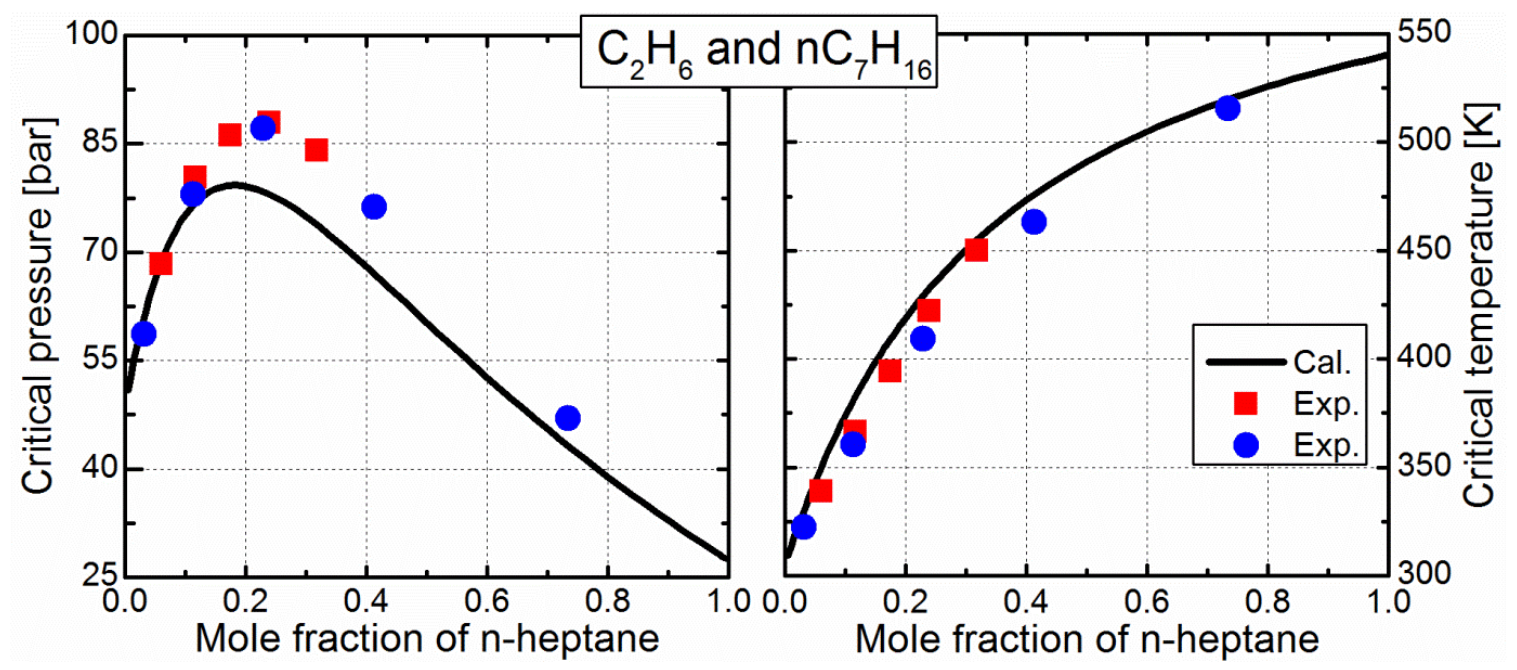

Fig. 3. Calculated critical point using Helmholtz free energy minimization compared to experimental data for ethane and n-heptane mixtures.

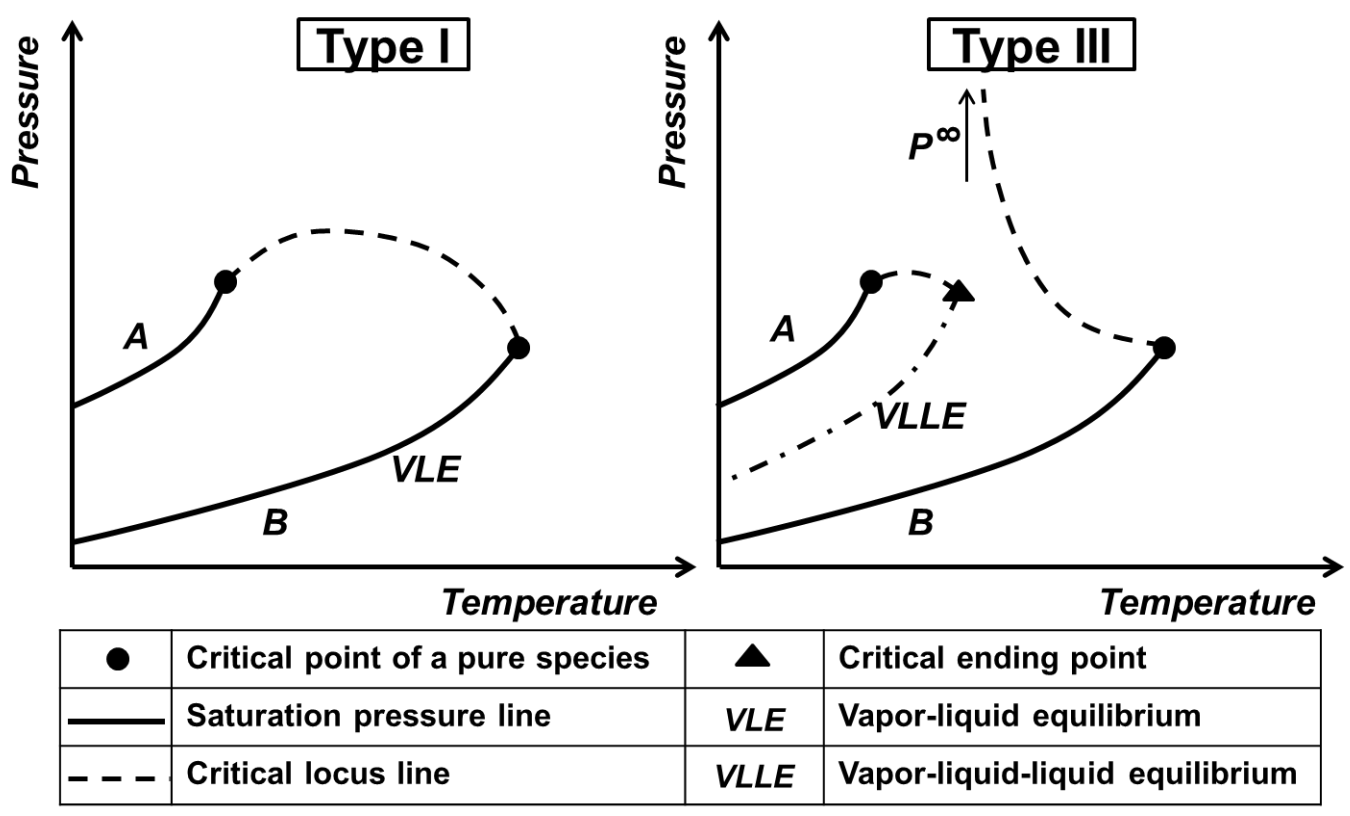

Fig. 4. Phase diagrams of two mixture types: Type I for hydrocarbon mixtures and Type III for binary mixtures of n-alkane and nitrogen. There is only one critical locus line for a Type I mixture, which starts from the critical point of species A and ends at the critical point of species B. There are two critical lines for Type III mixtures. One is the critical locus line that starts from the critical point of the pure alkane (B) and ends at infinite pressure. The other line is the critical locus line that starts from the critical point of pure nitrogen (A) and ends at the end point of the three-phase VLLE coexistence line (dash-dotted line). 


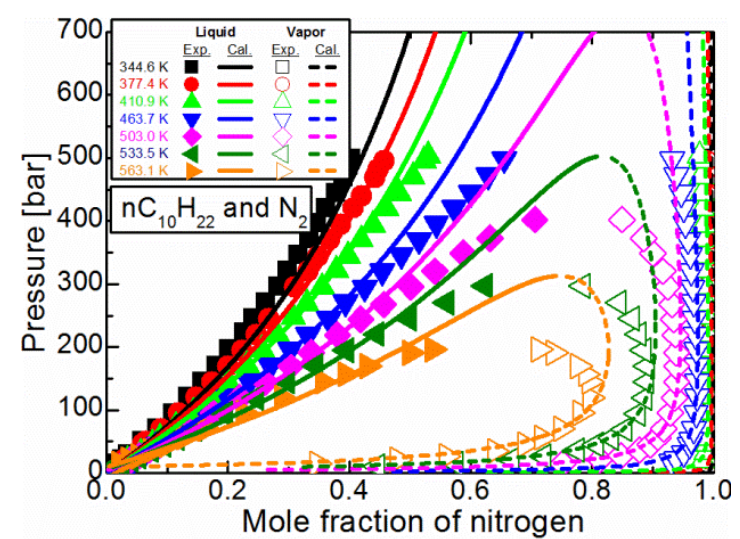

(a)

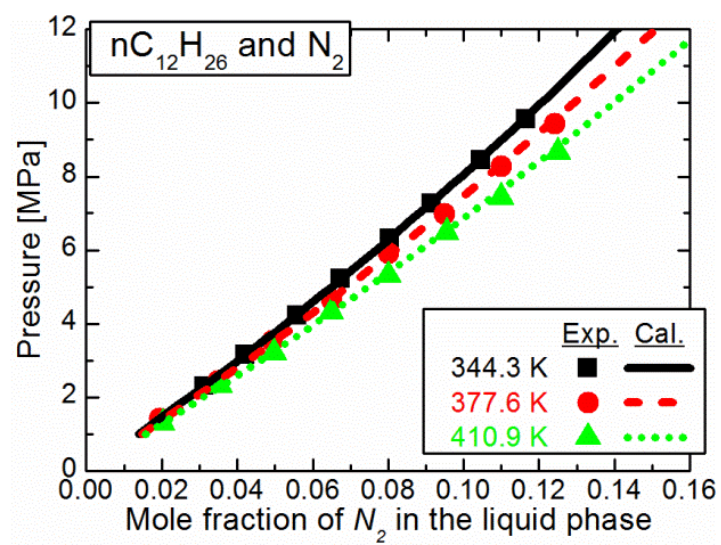

(b)

Fig. 5. Comparison of vapor-liquid equilibrium calculations of binary mixtures with experiments. (a) n-decane and nitrogen. (b) n-dodecane and nitrogen.

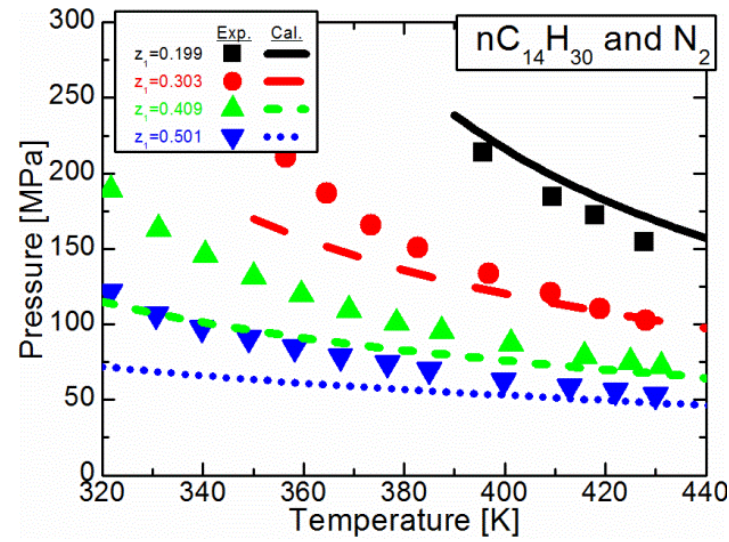

(a)

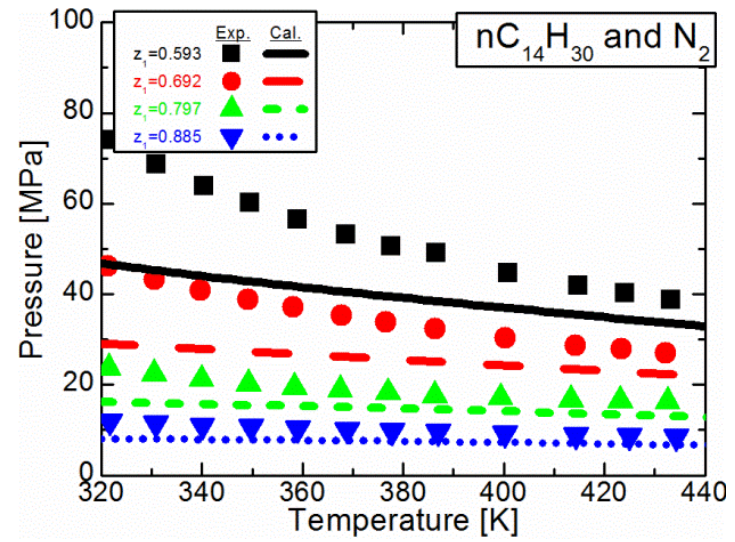

(b)

Fig. 6. Comparison of bubble pressure calculations with experimental data for n-tetradecane and nitrogen mixtures. 


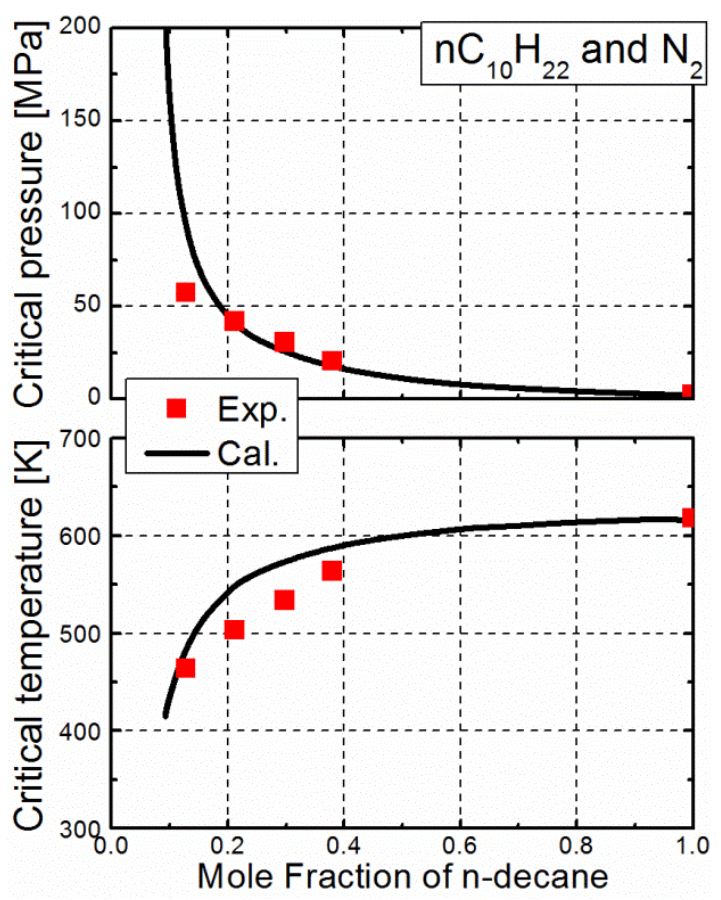

(a)
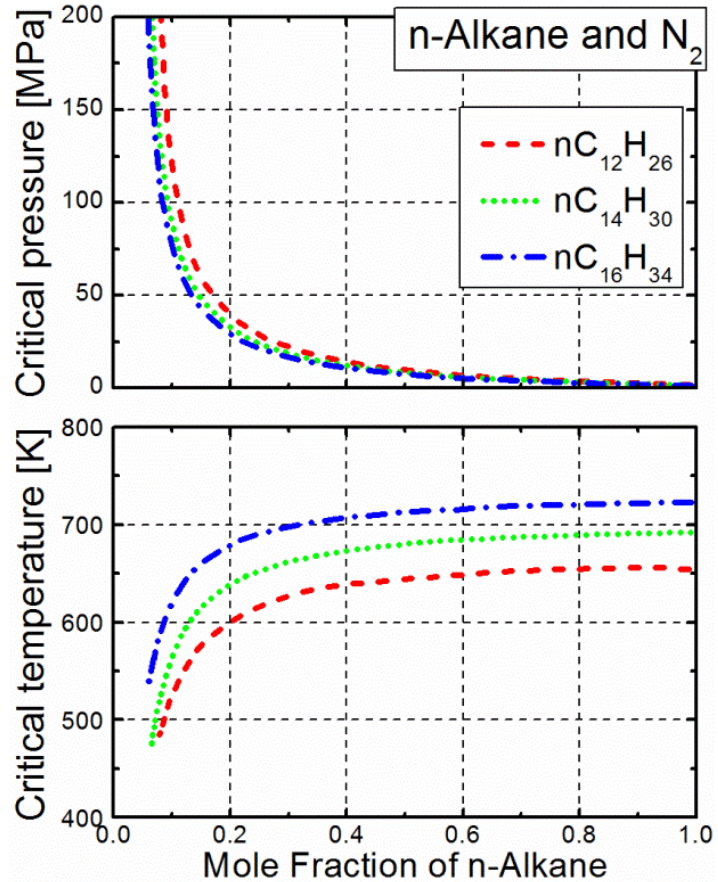

(b)

Fig. 7. Critical points of binary mixtures of n-alkane and nitrogen. (a) n-decane. (b) n-dodecane, n-tetradecane and n-hexadecane.

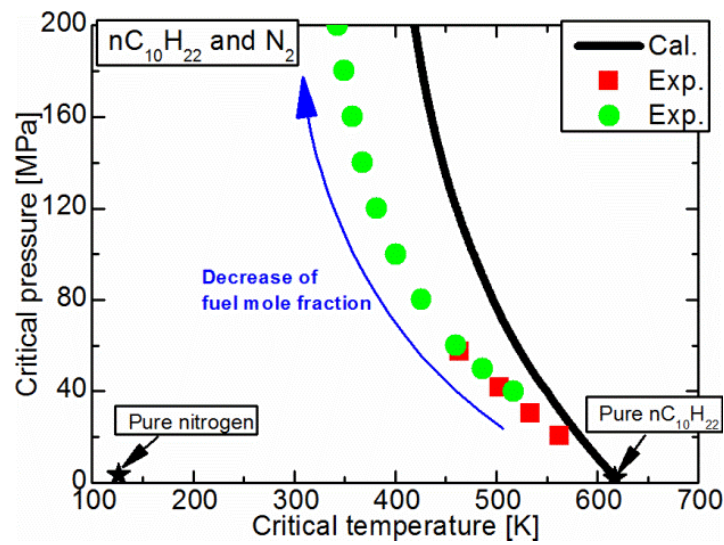

(a)

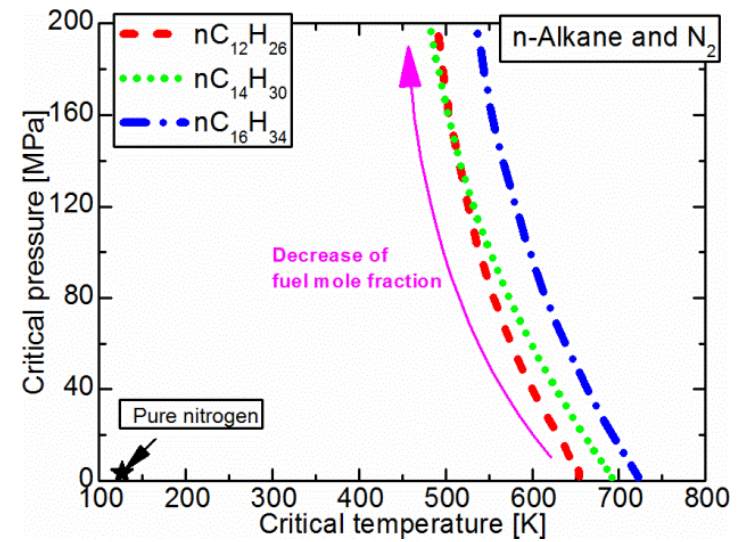

(b)

Fig. 8. Critical pressure-temperature diagrams of binary mixtures of n-alkane and nitrogen. (a) ndecane. (b) n-dodecane, n-tetradecane and n-hexadecane. Also shown are the critical points of pure nitrogen and pure n-decane. 


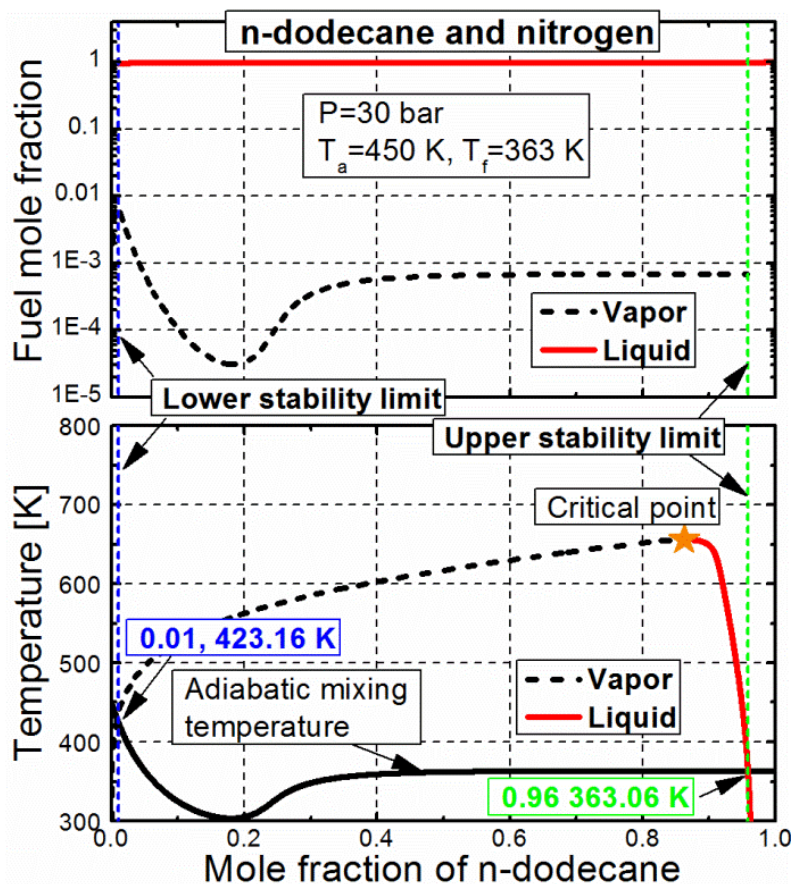

(a)

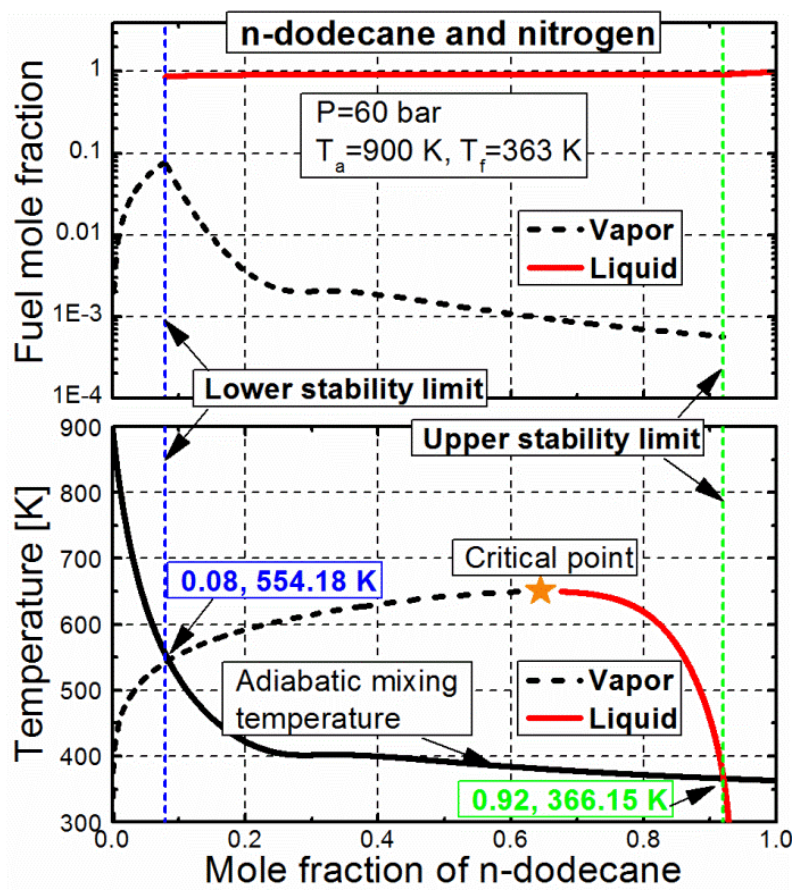

(b)

Fig. 9. Frozen adiabatic mixing temperature superimposed on the vapor-liquid equilibrium calculations for mixtures of n-dodecane and nitrogen. (a) 30 bar and $450 \mathrm{~K}$. (b) 60 bar and $900 \mathrm{~K}$. The lower and upper stability limits are shown in vertical dashed lines to indicate the beginning and end of the two-phase region. The top figure shows the calculated corresponding fuel mole fraction in each phase according to the frozen adiabatic mixing temperature. 


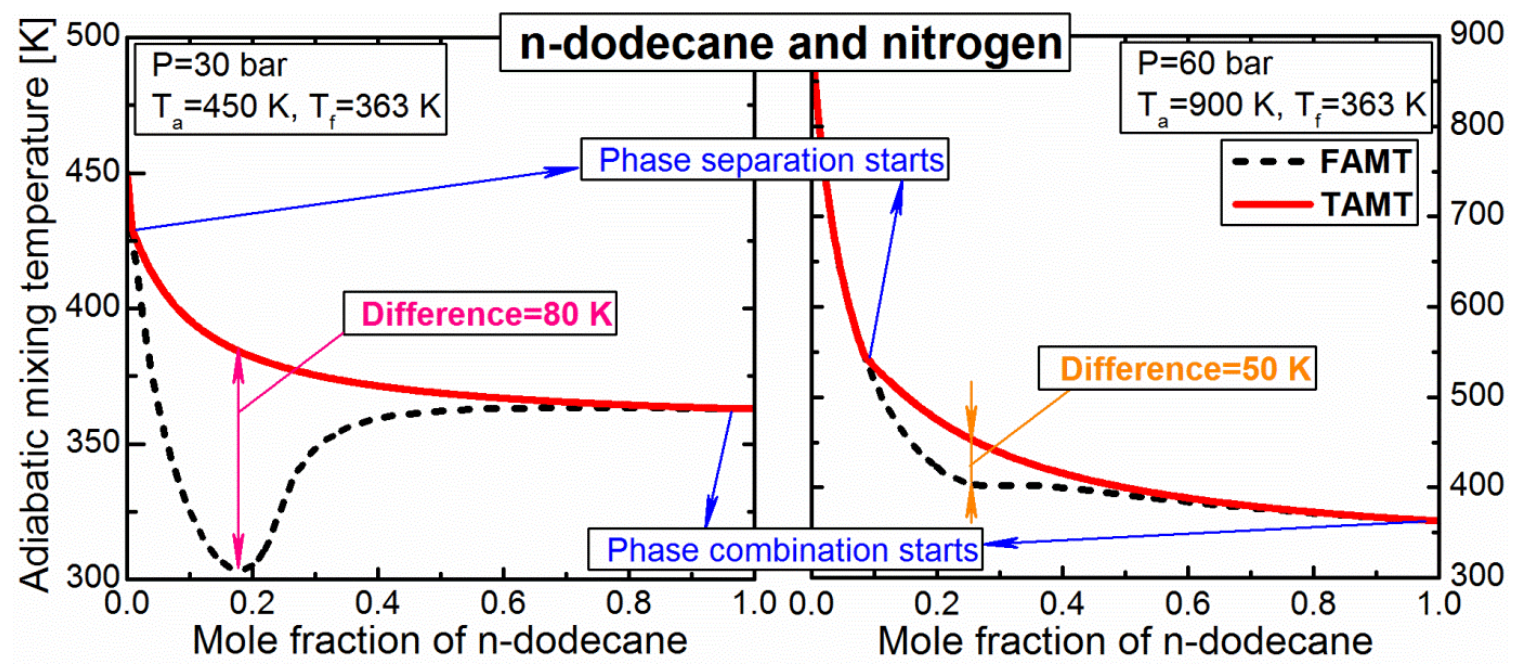

Fig. 10. Comparison of frozen and true adiabatic mixing temperatures (FAMT and TAMT) for mixtures of n-dodecane and nitrogen at 30 bar and $450 \mathrm{~K}$ (left) and 60 bar and $900 \mathrm{~K}$ (right). In both cases, phase separation starts when a small amount of fuel is introduced.

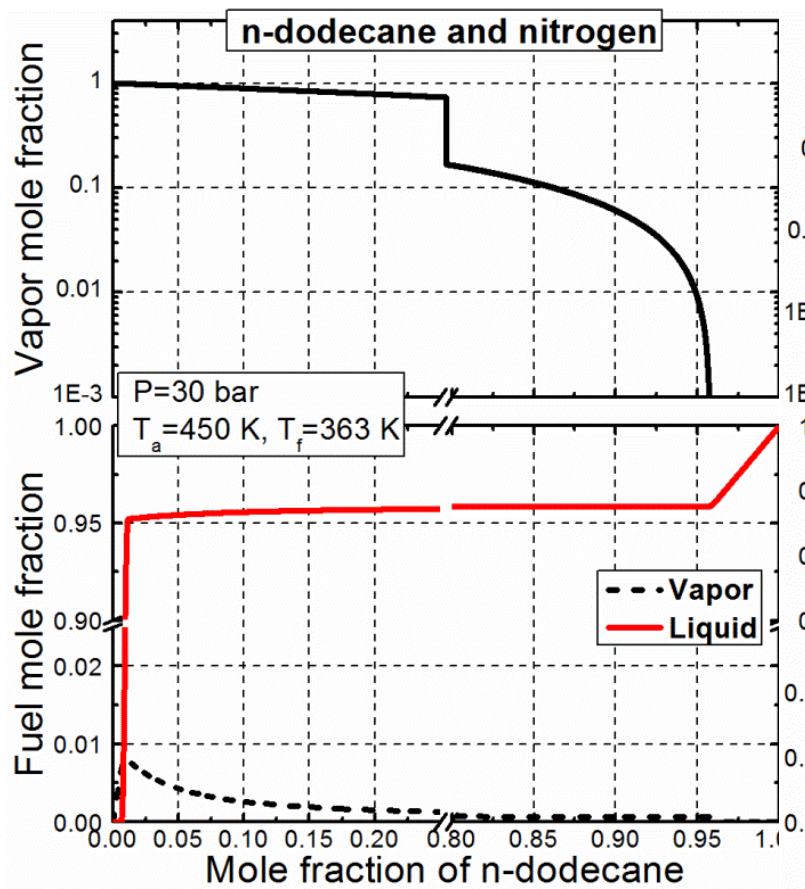

(a)

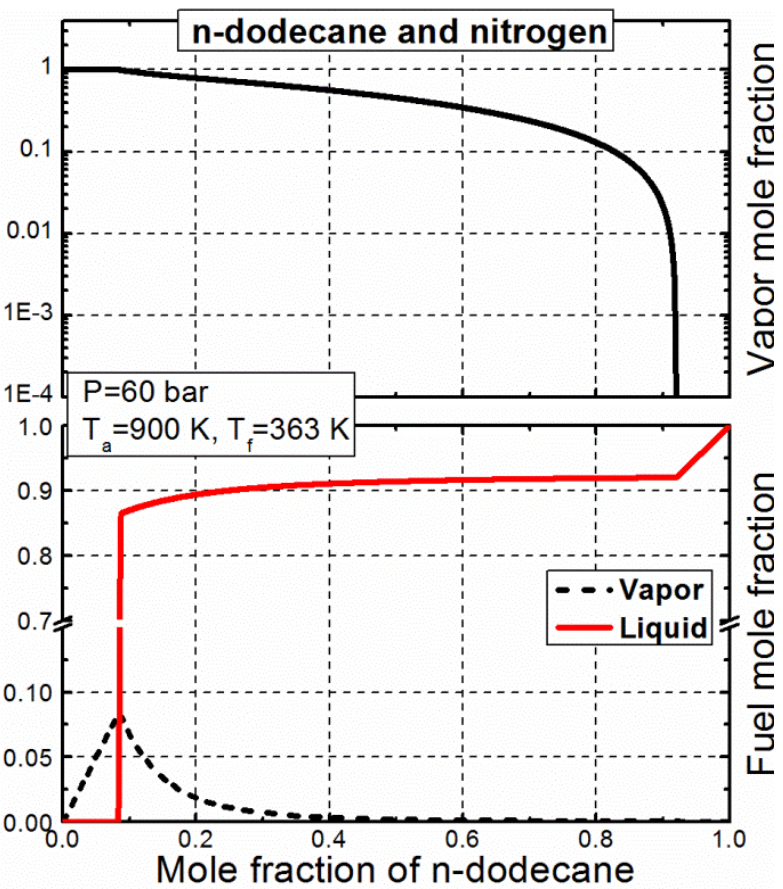

(b)

Fig. 11. Equilibrium vapor phase mole fraction and fuel mole fraction for true adiabatic mixing temperature for mixtures of n-dodecane and nitrogen. (a) 30 bar and $450 \mathrm{~K}$ (b) 60 bar and $900 \mathrm{~K}$. 


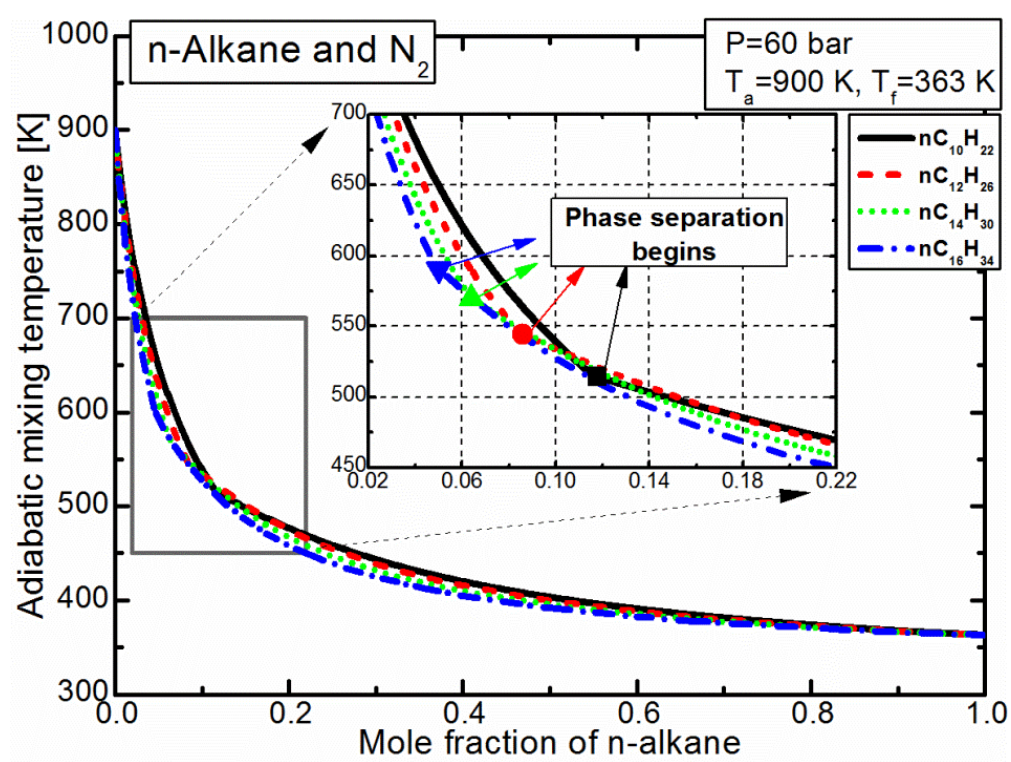

Fig. 12. Comparison of true adiabatic mixing temperature (TAMT) for mixtures of n-alkane (ndecane, n-dodecane, n-tetradecane and n-hexadecane) and nitrogen at $900 \mathrm{~K}$ and 60 bar. The temperature at which phase separation occurs for the four mixtures is shown with symbols in the enlarged plot.

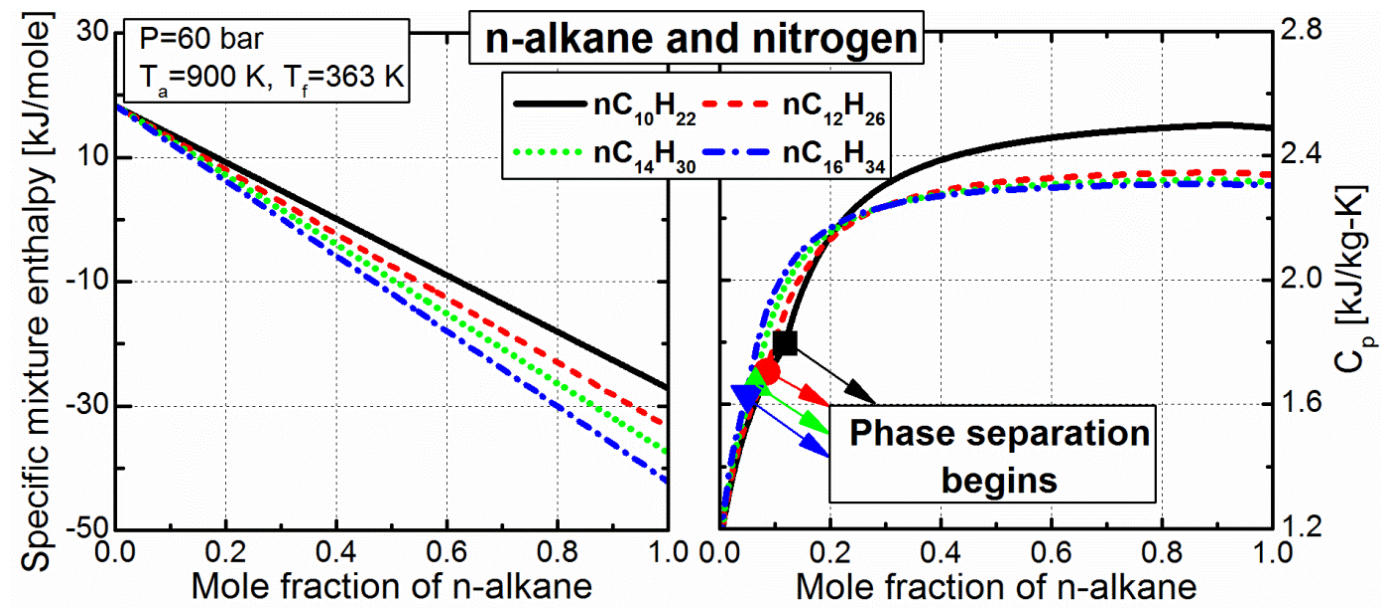

Fig. 13. Mixture enthalpy (left) and isobaric specific heat (right) of mixtures of n-alkane (ndecane, n-dodecane, n-tetradecane and n-hexadecane) and nitrogen at $900 \mathrm{~K}$ and 60 bar. Fuel mixture fraction at which phase separation occurs for the four mixtures is shown with symbols in the right plot. 


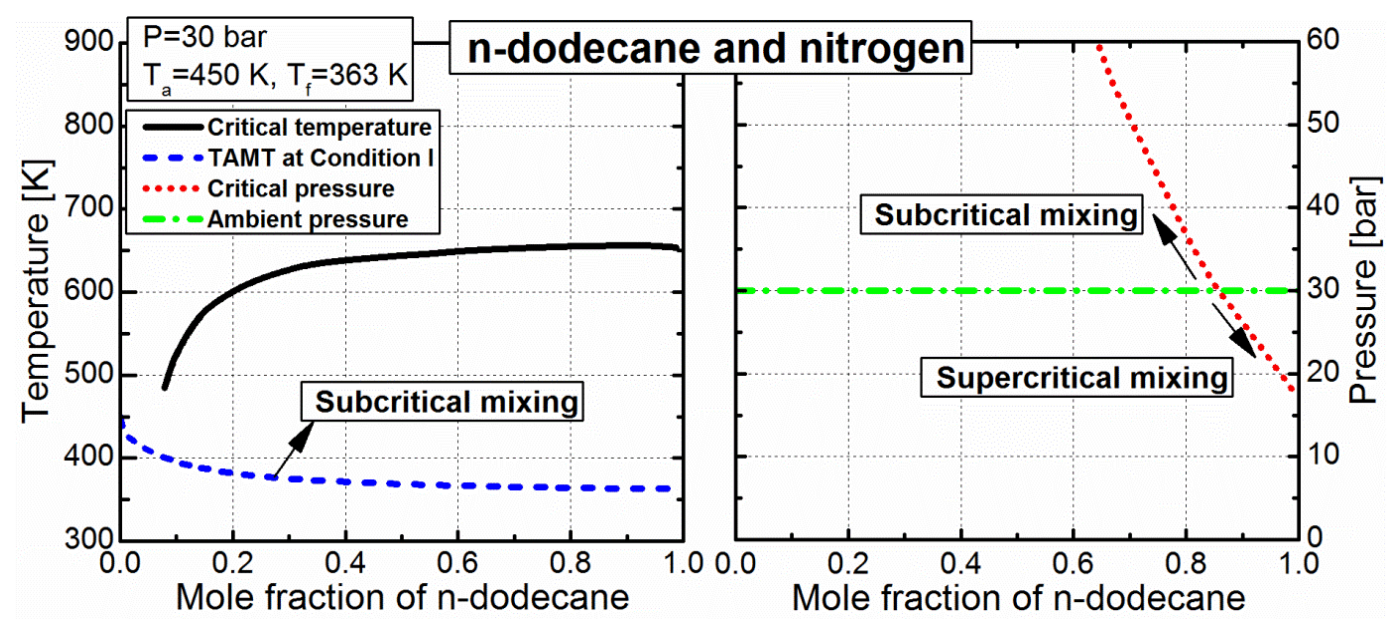

(a)

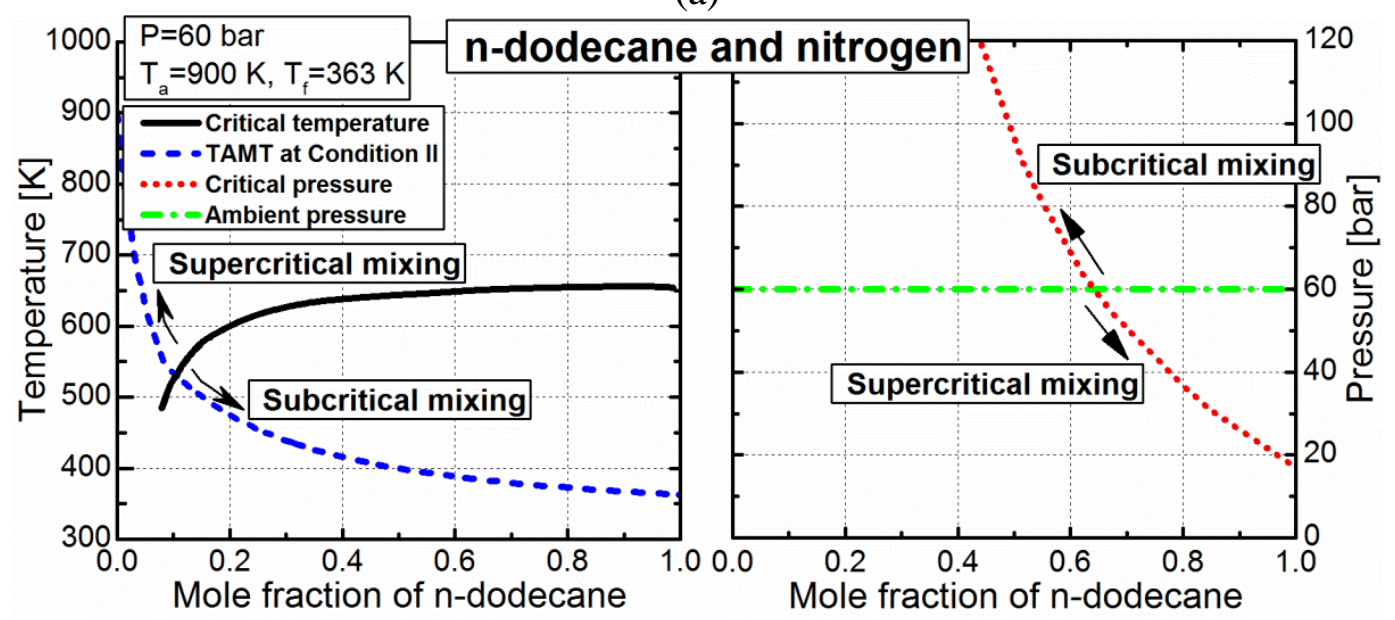

(b)

Fig. 14. Superimposed adiabatic mixing properties on the critical locus for mixtures of ndodecane and nitrogen. (a) 30 bar and $450 \mathrm{~K}$ (b) 60 bar and $900 \mathrm{~K}$. Left figure is the true adiabatic mixing temperature (TAMT) with the mixture critical temperature. Right figure shows ambient pressure and mixture critical pressure. Supercritical mixing refers to mixing when TAMT or ambient pressure is higher than the corresponding mixture critical property. Subcritical mixing refers to mixing when TAMT or ambient pressure is lower than the corresponding mixture critical property.. 


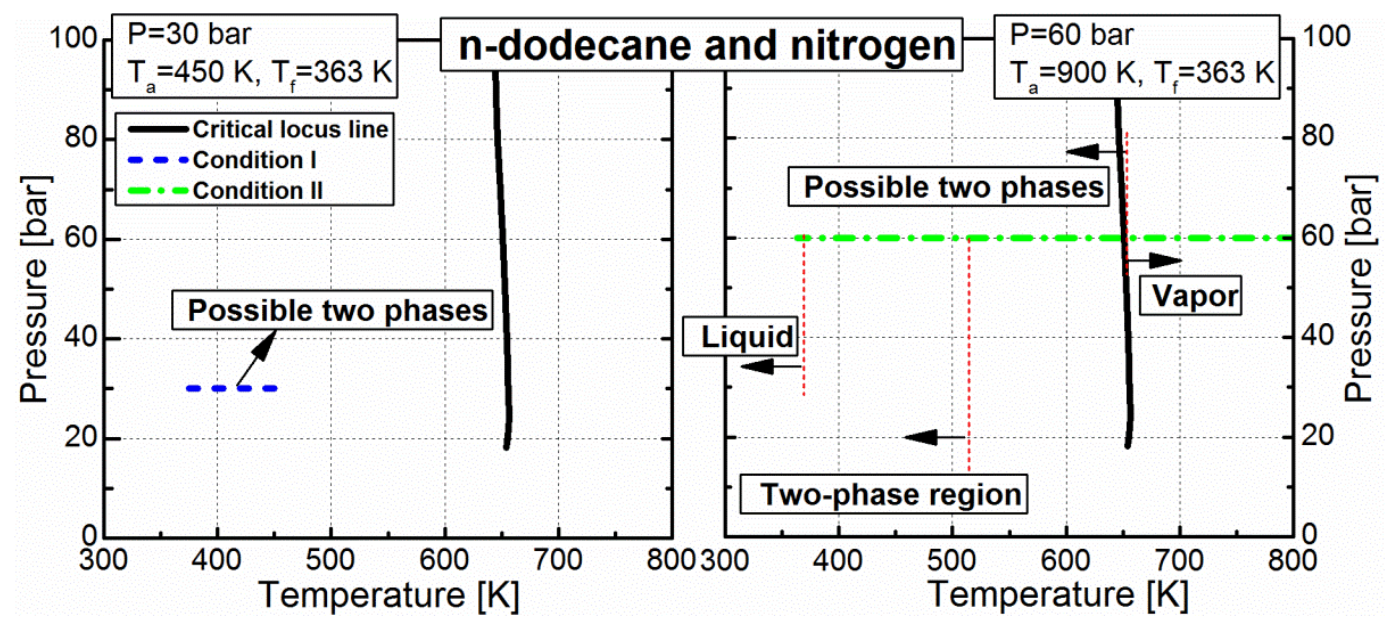

Fig. 15. Superimposed adiabatic mixing properties on the critical locus for mixtures of ndodecane and nitrogen at two conditions.

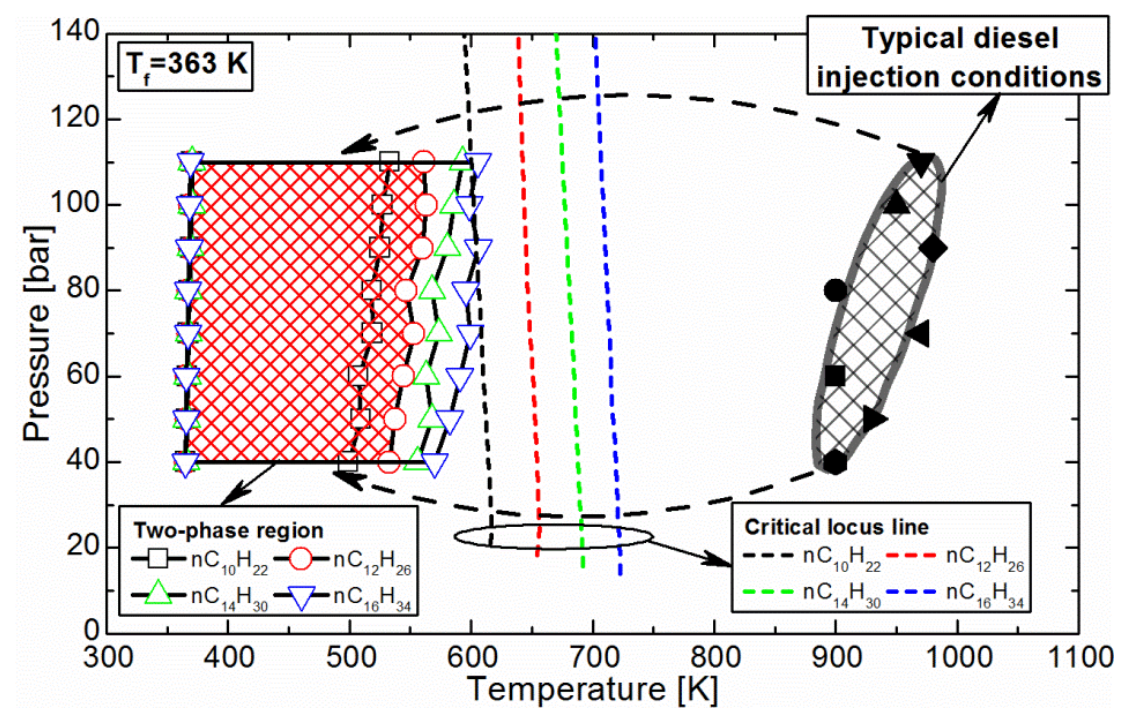

Fig. 16. Calculated two-phase region (area enclosed by lines with open symbols) for mixtures of n-alkane and nitrogen compared to typical injection conditions for diesel engines (crosshatch area to the right). The two-phase region for $\mathrm{nC}_{12} \mathrm{H}_{26} / \mathrm{N}_{2}$ mixtures is highlighted with red dense crosshatch. Also shown are the critical locus lines for the four mixtures. 


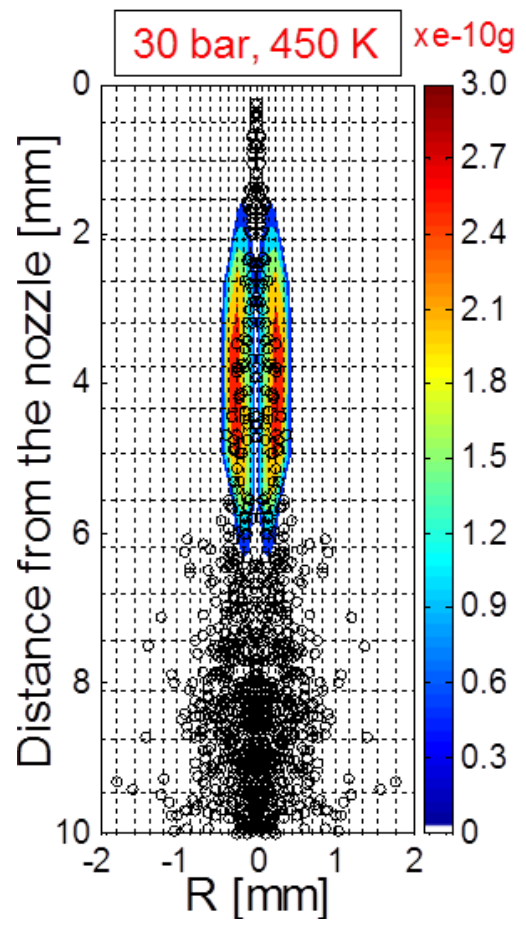

(a)

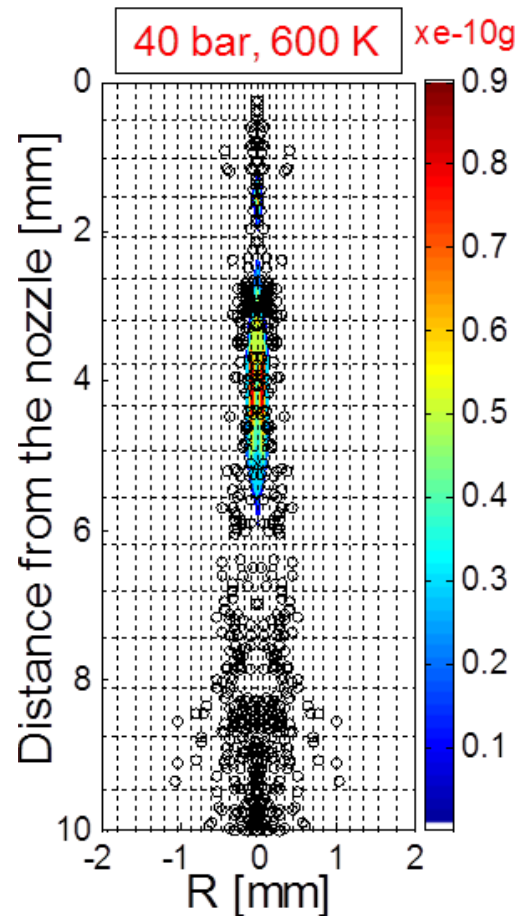

(b)

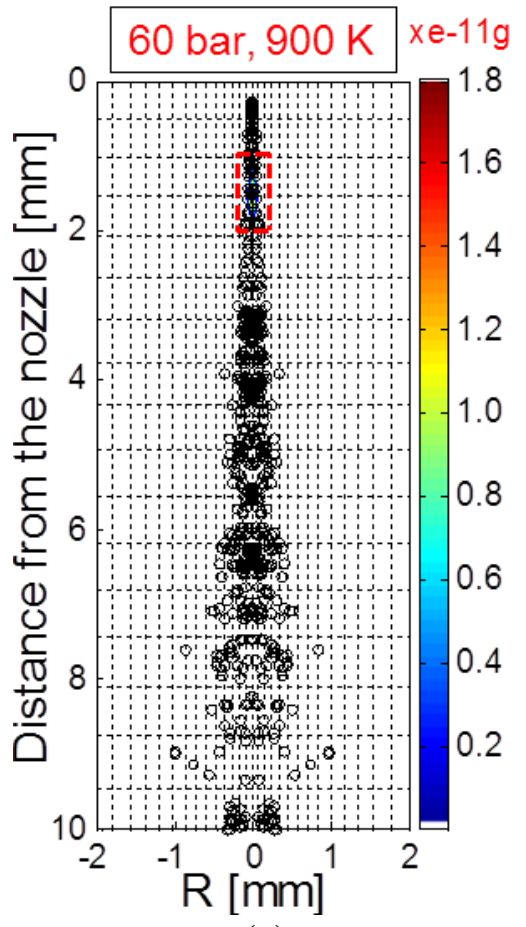

(c)

Fig. 17. Condensed liquid fuel mass during high-pressure injection of n-dodecane into a nitrogen environment. (a) $0.7 \mathrm{~ms}$ ASI for Condition I. (b) $0.3 \mathrm{~ms}$ ASI for Condition III. (c) $0.56 \mathrm{~ms}$ ASI for Condition II, with the condensation region in the red box. Dashed lines represent the meshes used. Circles show droplet locations. 

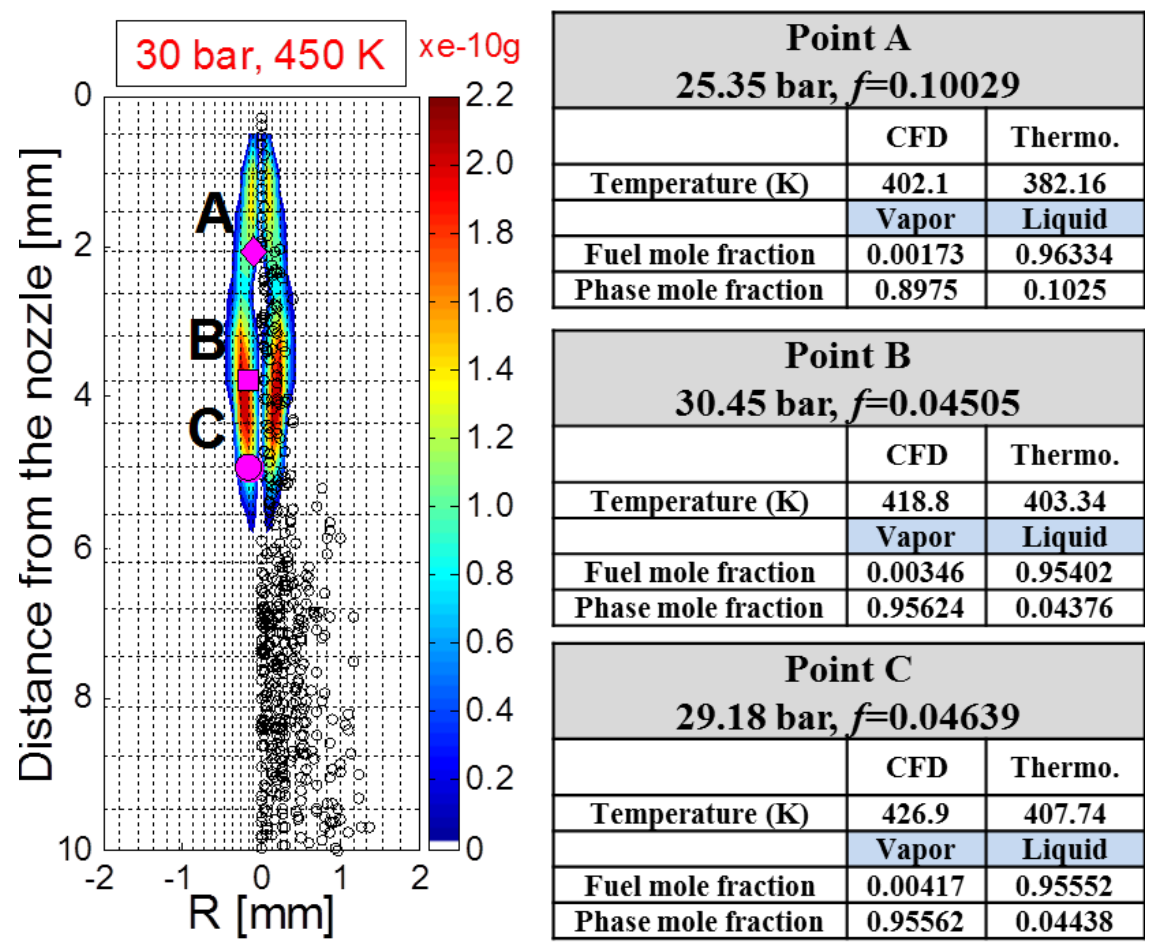

\begin{tabular}{|c|c|c|}
\hline \multicolumn{3}{|c|}{ Point B } \\
30.45 bar, $f=0.04505$ \\
\hline & CFD & Thermo. \\
\hline Temperature (K) & 418.8 & 403.34 \\
\hline & Vapor & Liquid \\
\hline Fuel mole fraction & $\mathbf{0 . 0 0 3 4 6}$ & $\mathbf{0 . 9 5 4 0 2}$ \\
\hline Phase mole fraction & $\mathbf{0 . 9 5 6 2 4}$ & $\mathbf{0 . 0 4 3 7 6}$ \\
\hline
\end{tabular}

\begin{tabular}{|c|c|c|}
\hline \multicolumn{3}{|c|}{ Point C } \\
29.18 bar, $f=0.04639$ \\
\hline & CFD & Thermo. \\
\hline Temperature (K) & 426.9 & 407.74 \\
\hline & Vapor & Liquid \\
\hline Fuel mole fraction & $\mathbf{0 . 0 0 4 1 7}$ & $\mathbf{0 . 9 5 5 5 2}$ \\
\hline Phase mole fraction & $\mathbf{0 . 9 5 5 6 2}$ & $\mathbf{0 . 0 4 4 3 8}$ \\
\hline
\end{tabular}

(a)

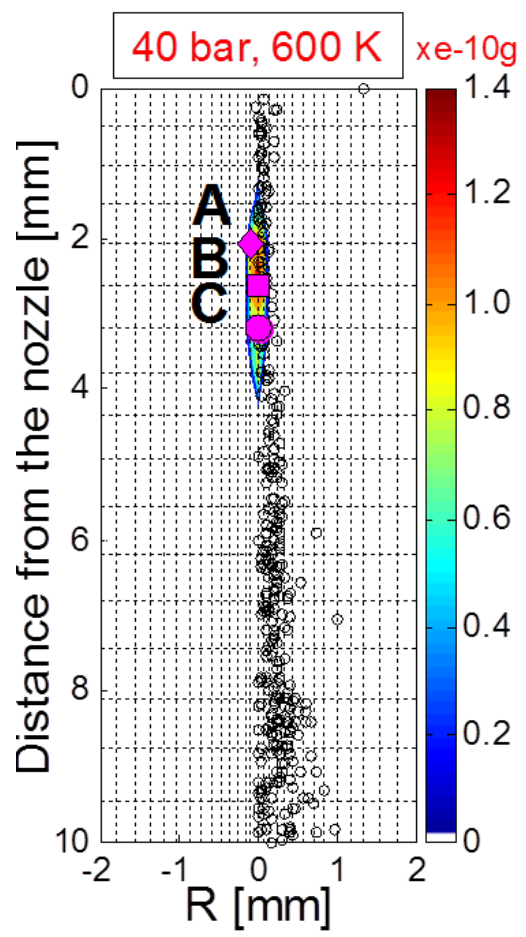

\begin{tabular}{|c|c|c|}
\hline \multicolumn{3}{|c|}{ Point A } \\
38. 1 bar, $f=0.12279$ \\
\hline & CFD & Thermo. \\
\hline Temperature (K) & 480.6 & 426.79 \\
\hline & Vapor & Liquid \\
\hline Fuel mole fraction & $\mathbf{0 . 0 0 6 5 7}$ & 0.93977 \\
\hline Phase mole fraction & $\mathbf{0 . 8 7 5 4 7}$ & $\mathbf{0 . 1 2 4 5 3}$ \\
\hline
\end{tabular}

\begin{tabular}{|c|c|c|}
\hline \multicolumn{3}{|c|}{ Point B } \\
39.58 bar, $f=0.43516$ \\
\hline & CFD & Thermo. \\
\hline Temperature (K) & 438.1 & 375.81 \\
\hline & Vapor & Liquid \\
\hline Fuel mole fraction & 0.00102 & 0.94464 \\
\hline Phase mole fraction & $\mathbf{0 . 5 3 9 9 1}$ & $\mathbf{0 . 4 6 0 0 9}$ \\
\hline
\end{tabular}

\begin{tabular}{|c|c|c|}
\hline \multicolumn{3}{|c|}{ Point C } \\
38.43 bar, $f=0.04812$ \\
\hline & CFD & Thermo. \\
\hline Temperature (K) & 458.6 & 447.64 \\
\hline & Vapor & Liquid \\
\hline Fuel mole fraction & $\mathbf{0 . 0 1 2 1 5}$ & 0.9357 \\
\hline Phase mole fraction & $\mathbf{0 . 9 6 1 0 6}$ & $\mathbf{0 . 0 3 8 9 4}$ \\
\hline
\end{tabular}

(b) 

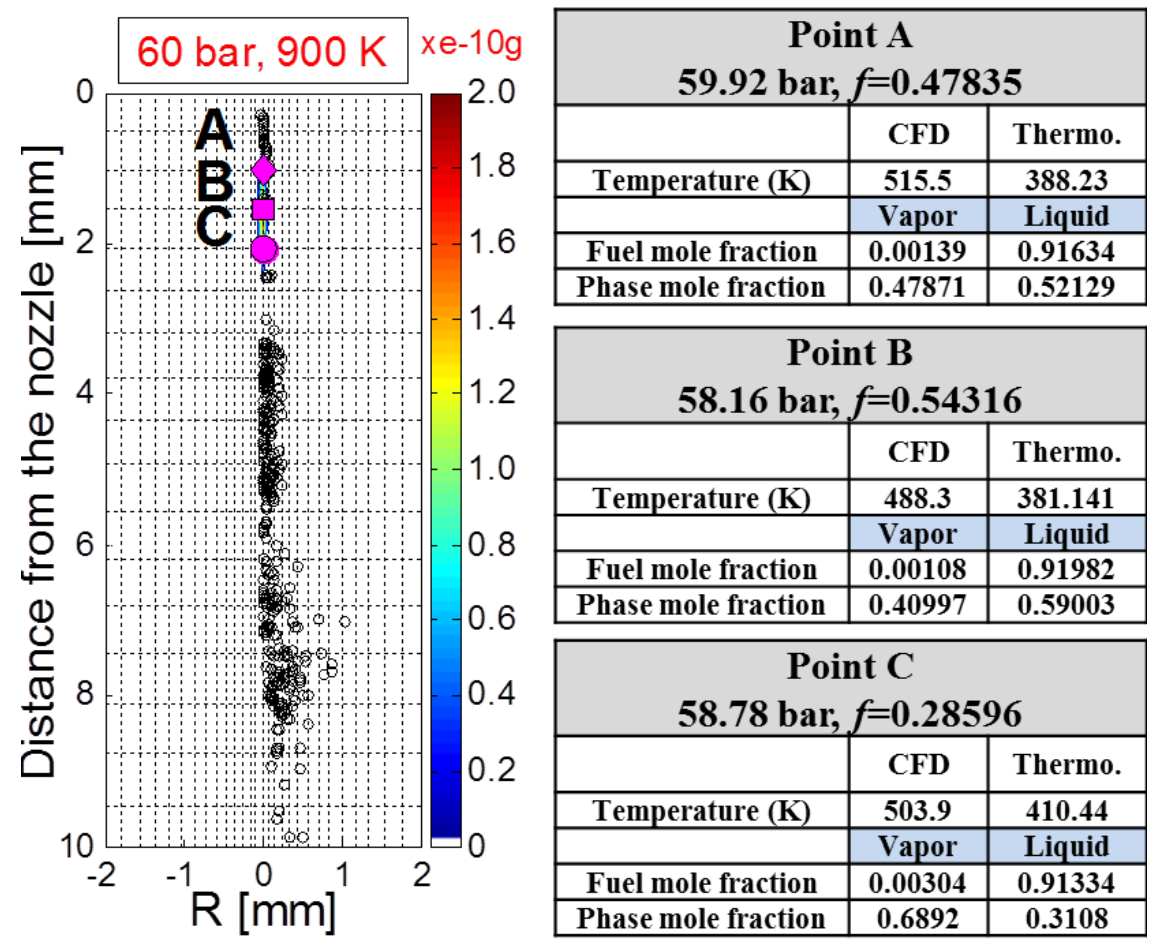

\begin{tabular}{|c|c|c|}
\hline \multicolumn{3}{|c|}{ Point C } \\
58.78 bar, $f=0.28596$ \\
\hline & CFD & Thermo. \\
\hline Temperature (K) & 503.9 & 410.44 \\
\hline & Vapor & Liquid \\
\hline Fuel mole fraction & $\mathbf{0 . 0 0 3 0 4}$ & $\mathbf{0 . 9 1 3 3 4}$ \\
\hline Phase mole fraction & $\mathbf{0 . 6 8 9 2}$ & $\mathbf{0 . 3 1 0 8}$ \\
\hline
\end{tabular}

(c)

Fig. 18. Phase equilibrium calculations at selected spatial locations during high-pressure injection of n-dodecane into a nitrogen environment. (a) $0.6 \mathrm{~ms}$ ASI for Condition I. (b) $0.4 \mathrm{~ms}$ ASI for Condition III. (c) $0.16 \mathrm{~ms}$ ASI for Condition II. $f$ is the fuel mixture fraction, including both the liquid and gas phases. Circles to the right of jet centerline show droplet locations. Left of jet centerline shows condensed mass contours. Temperatures determined from CFD and thermodynamics calculations are presented in the tables, where the equilibrium distributions are tabulated. 


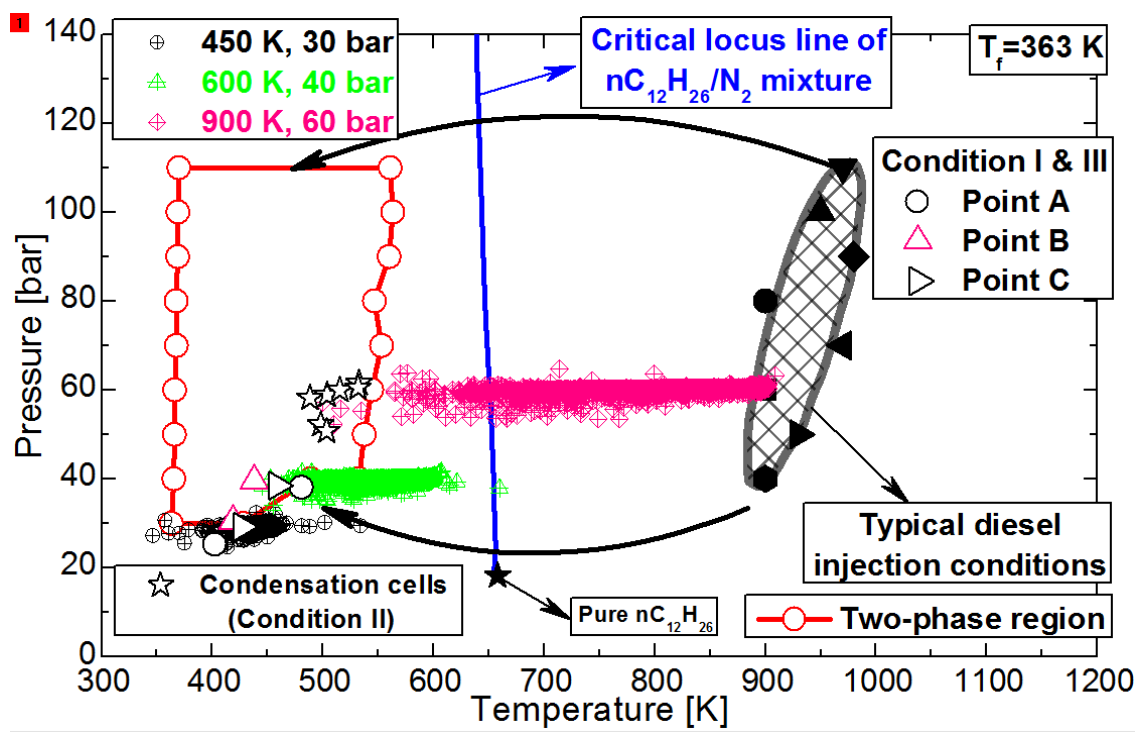

Fig. 19. Superimposed two-phase region from thermodynamic analysis for mixtures of $n$ dodecane and nitrogen, and the local thermodynamic conditions determined from CFD simulations of high-pressure injection of n-dodecane into a nitrogen environment. Note that the two-phase region is enlarged compared to Fig. 16 due to the inclusion of Conditions I and III. Points A, B and C with condensation from Fig. 18 for Conditions I and III are shown while some selected condensation cells for Condition II are indicated with black star symbols. 
Table 1. Thermodynamic properties of hydrocarbon species.

\begin{tabular}{|c|c|c|c|c|}
\hline species & $\begin{array}{c}\boldsymbol{T}_{\boldsymbol{c}} \\
(\mathbf{K})\end{array}$ & $\begin{array}{c}\boldsymbol{P}_{c} \\
\text { (bar) }\end{array}$ & $\begin{array}{l}\boldsymbol{\omega} \\
(-)\end{array}$ & $\begin{array}{c}\delta_{i, C_{2} H_{6}} \\
(-)\end{array}$ \\
\hline $\mathrm{C}_{2} \mathrm{H}_{6}$ & 305.32 & 48.72 & 0.0995 & \\
\hline $\mathrm{nC}_{7} \mathrm{H}_{16}$ & 540.3 & 27.36 & 0.3495 & 0.019 \\
\hline
\end{tabular}

Table 2. Thermodynamic properties of $n$-alkanes and nitrogen.

\begin{tabular}{|c|c|c|c|c|}
\hline species & $\begin{array}{c}\boldsymbol{T}_{\boldsymbol{c}} \\
(\mathbf{K})\end{array}$ & $\begin{array}{c}\boldsymbol{P}_{\boldsymbol{c}} \\
(\text { bar) }\end{array}$ & $\begin{array}{c}\boldsymbol{\omega} \\
(-)\end{array}$ & $\begin{array}{c}\boldsymbol{\delta}_{\boldsymbol{i}, \boldsymbol{N}_{\mathbf{2}}} \\
(-)\end{array}$ \\
\hline $\mathrm{N}_{2}$ & 126.2 & 33.9 & 0.0377 & \\
\hline $\mathrm{nC}_{10} \mathrm{H}_{22}$ & 617.7 & 21.1 & 0.4923 & 0.1597 \\
\hline $\mathrm{nC}_{12} \mathrm{H}_{26}$ & 658.0 & 18.2 & 0.5764 & 0.2082 \\
\hline $\mathrm{nC}_{14} \mathrm{H}_{30}$ & 693.0 & 15.7 & 0.643 & 0.1506 \\
\hline $\mathrm{nC}_{16} \mathrm{H}_{34}$ & 723.0 & 14.0 & 0.7174 & 0.1816 \\
\hline
\end{tabular}

Table 3. Comparison of solutions with and without phase stability for the n-dodecane and nitrogen mixture.

\begin{tabular}{|c|c|c|}
\hline \multicolumn{3}{|c|}{$\mathrm{P}_{\mathrm{a}}=60$ bar, $\mathrm{T}_{\mathrm{a}}=900 \mathrm{~K}, \mathrm{~T}_{\mathrm{f}}=363 \mathrm{~K}$ and $f=0.2$} \\
\hline Equilibrium properties & $\begin{array}{c}\text { Without phase } \\
\text { stability }\end{array}$ & $\begin{array}{c}\text { With phase } \\
\text { stability }\end{array}$ \\
\hline Temperature (K) & 422.16 (FAMT) & 475.17 (TAMT) \\
\hline Fuel mole fraction in the vapor phase & 0.2 & 0.01863 \\
\hline Fuel mole fraction in the liquid phase & NA & 0.89385 \\
\hline Vapor phase mole fraction & 1.0 & 0.79277 \\
\hline
\end{tabular}

Table 4. Spray simulation conditions.

\begin{tabular}{|c|c|c|c|}
\hline Ambient condition & I & II & III \\
\hline Ambient pressure (bar) & 30 & 60 & 40 \\
\hline Ambient temperature $(\mathrm{K})$ & 450 & 900 & 600 \\
\hline Ambient density $\left(\mathrm{kg} / \mathrm{m}^{3}\right)$ & \multicolumn{3}{|c|}{22.8} \\
\hline Ambient composition & \multicolumn{2}{|c|}{ Pure nitrogen } \\
\hline Fuel & n-dodecane $\left(\mathrm{nC}_{12} \mathrm{H}_{26}\right)$ \\
\hline nozzle diameter $(\mu \mathrm{m})$ & \multicolumn{2}{|c|}{90} \\
\hline Fuel temperature $(\mathrm{K})$ & \multicolumn{2}{|c|}{363} \\
\hline Injection pressure $(\mathrm{MPa})$ & \multicolumn{2}{|c|}{150} \\
\hline Injection duration $(\mathrm{ms})$ & \multicolumn{2}{|c|}{6.0} \\
\hline Discharge coefficient & \multicolumn{2}{|c|}{0.89} \\
\hline
\end{tabular}

